\title{
NMIS/FNMIS COMPARISON FOR US DOE OFFICE OF NUCLEAR VERIFICATION
}

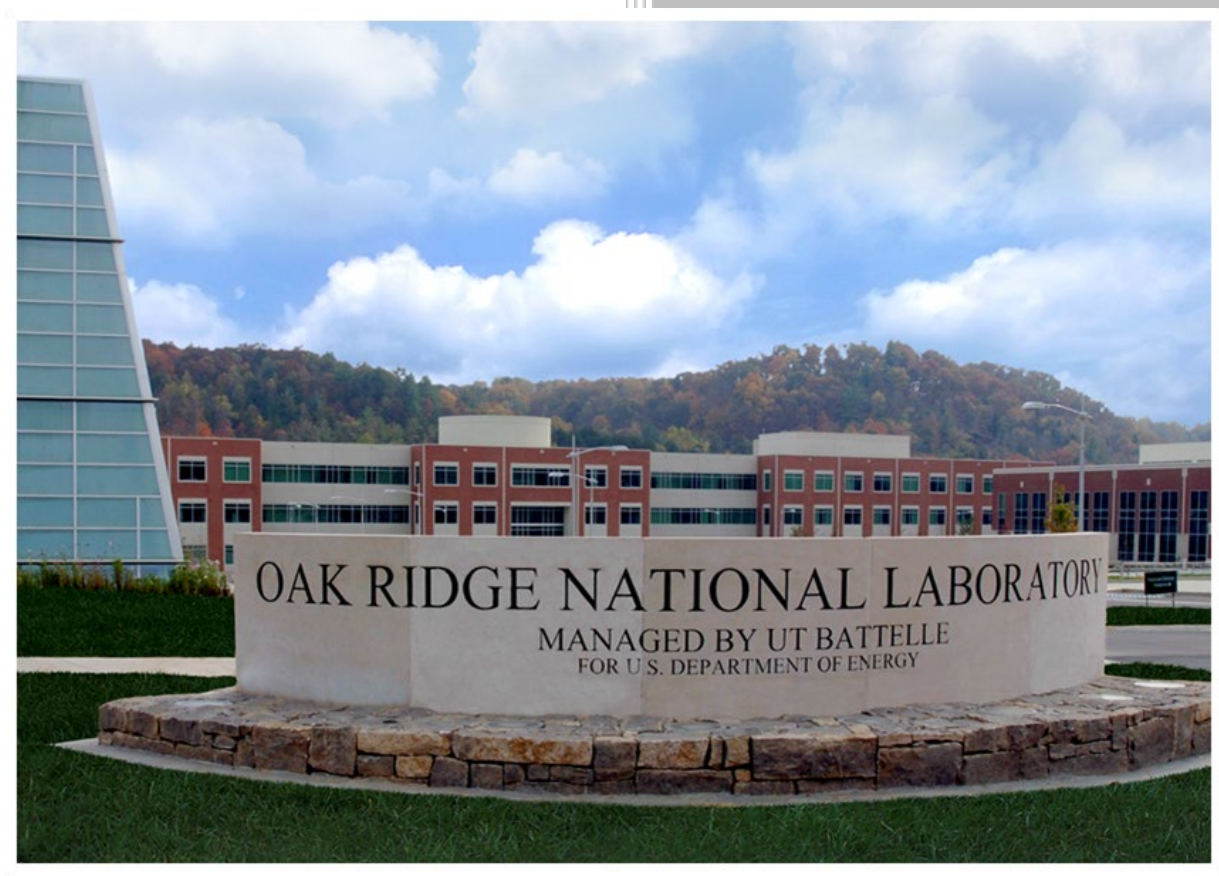

John T. Mihalczo

Blake A. Palles

Eric Nelius

Seth McConchie

September 15, 2017 


\section{DOCUMENT AVAILABILITY}

Reports produced after January 1, 1996, are generally available free via US Department of Energy (DOE) SciTech Connect.

Website http://www.osti.gov/scitech/

Reports produced before January 1, 1996, may be purchased by members of the public from the following source:

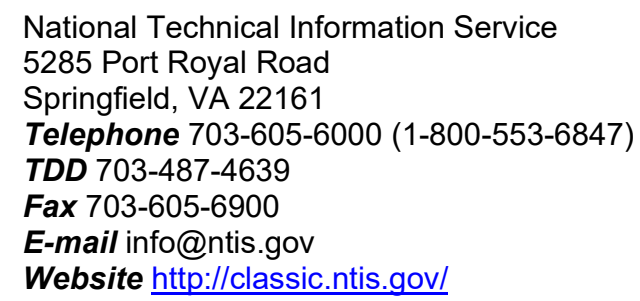

Reports are available to DOE employees, DOE contractors, Energy Technology Data Exchange representatives, and International Nuclear Information System representatives from the following source:

Office of Scientific and Technical Information

PO Box 62

Oak Ridge, TN 37831

Telephone 865-576-8401

Fax 865-576-5728

E-mail reports@osti.gov

Website http://www.osti.gov/contact.html

This report was prepared as an account of work sponsored by an agency of the United States Government. Neither the United States Government nor any agency thereof, nor any of their employees, makes any warranty, express or implied, or assumes any legal liability or responsibility for the accuracy, completeness, or usefulness of any information, apparatus, product, or process disclosed, or represents that its use would not infringe privately owned rights. Reference herein to any specific commercial product, process, or service by trade name, trademark, manufacturer, or otherwise, does not necessarily constitute or imply its endorsement, recommendation, or favoring by the United States Government or any agency thereof. The views and opinions of authors expressed herein do not necessarily state or reflect those of the United States Government or any agency thereof. 
Nuclear Security and Isotope Technology Division

\title{
NMIS/FNMIS COMPARISON FOR THE US DOE OFFICE OF NUCLEAR VERIFICATION
}

\author{
John T. Mihalczo \\ Blake A. Palles* \\ Eric Nelius** \\ Seth McConchie
}

*NNSA fellow on assignment to NA-22

**University of Tennessee student

Date Published: September 2017

Prepared by

OAK RIDGE NATIONAL LABORATORY

Oak Ridge, TN 37831-6283

managed by

UT-BATTELLE, LLC

for the

US DEPARTMENT OF ENERGY

under contract DE-AC05-00OR22725 
This page intentionally left blank. 


\section{CONTENTS}

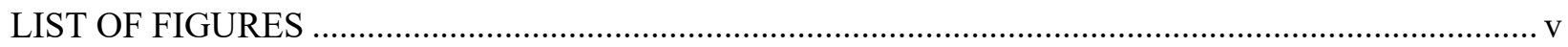

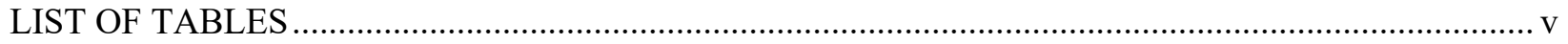

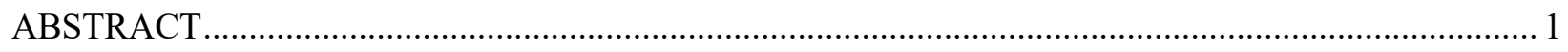

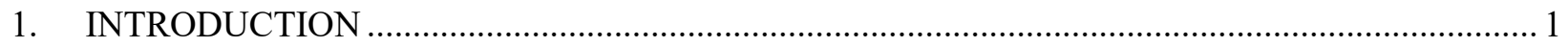

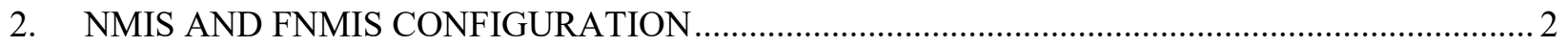

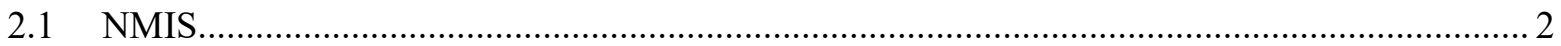

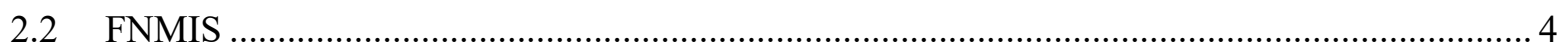

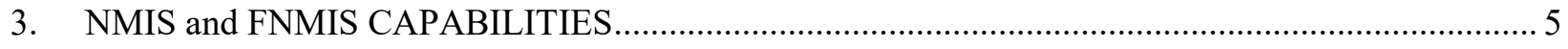

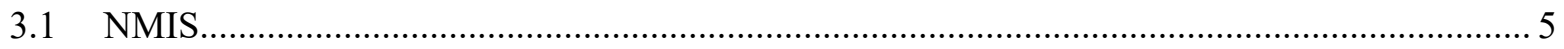

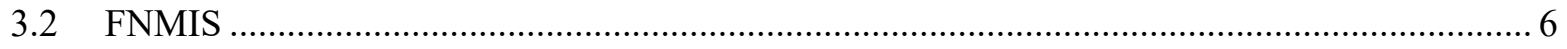

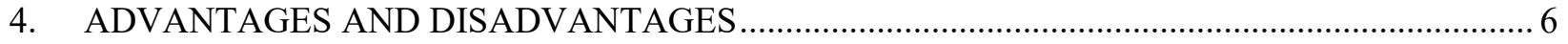

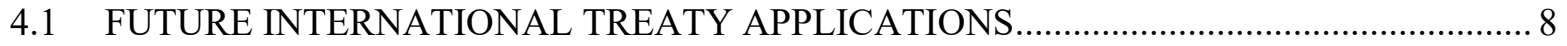

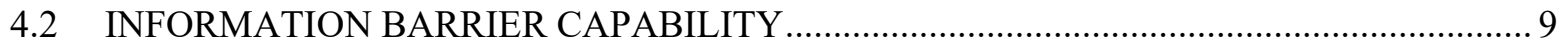

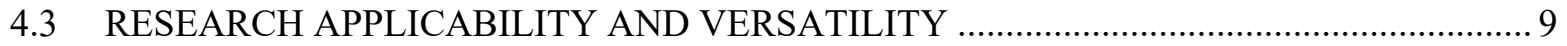

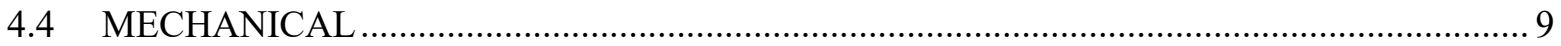

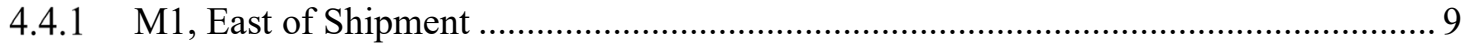

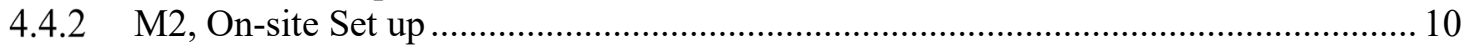

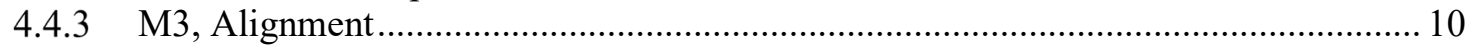

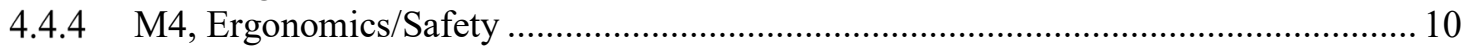

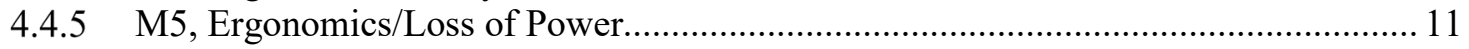

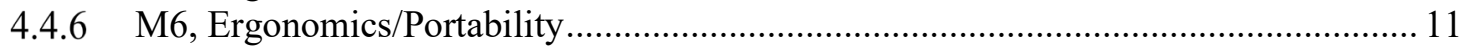

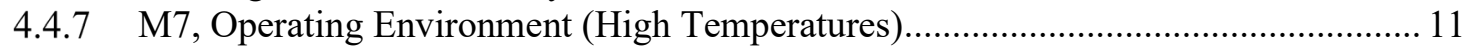

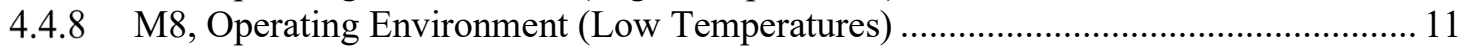

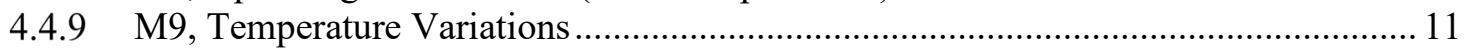

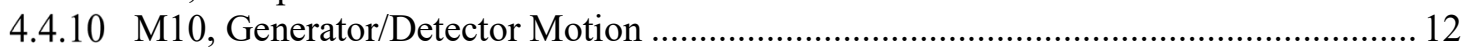

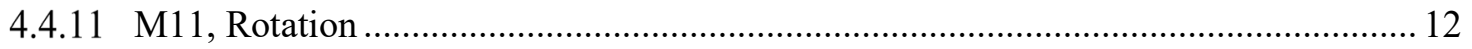

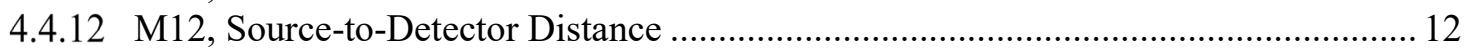

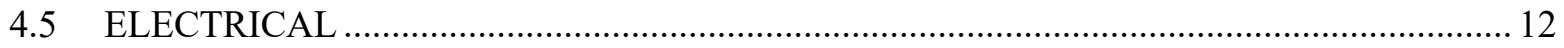

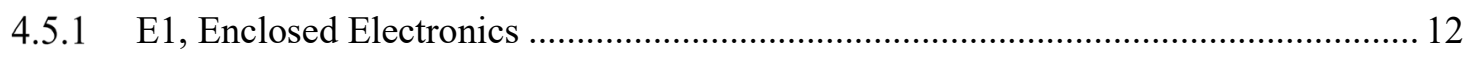

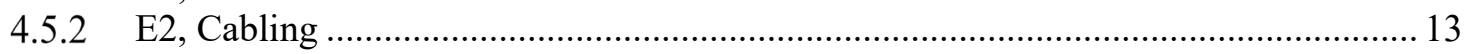

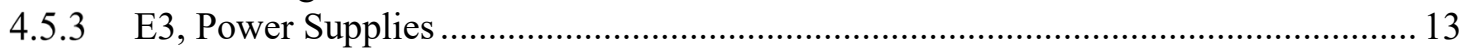

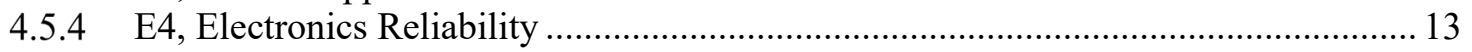

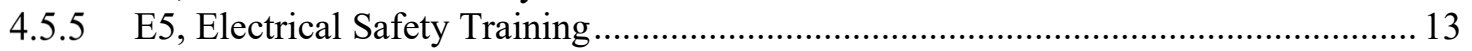

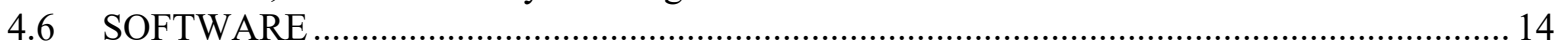

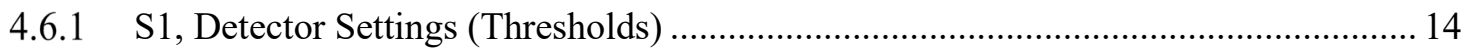

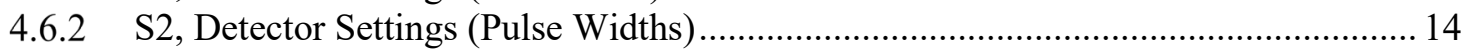

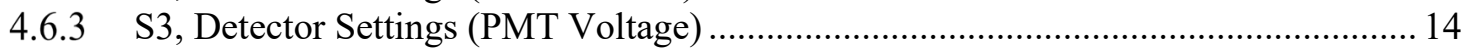

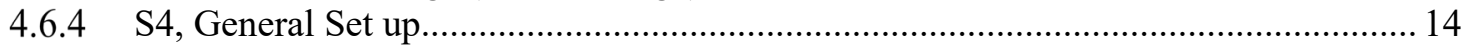

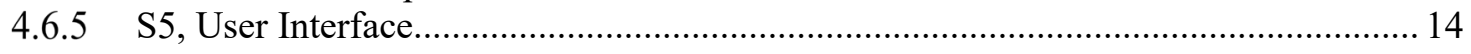

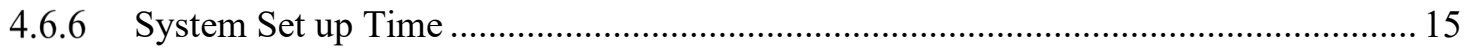

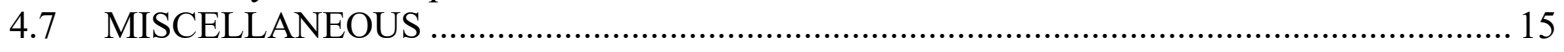

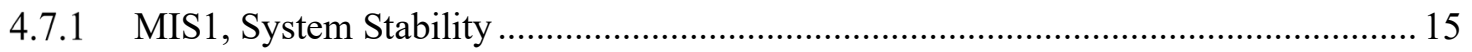

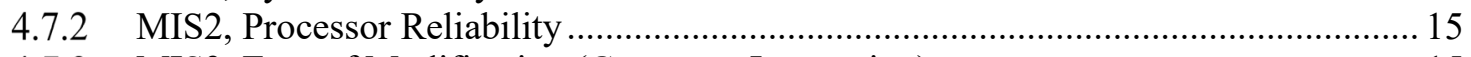

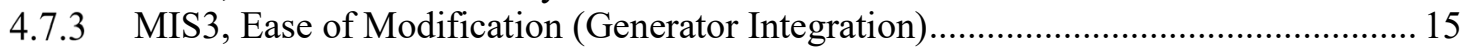

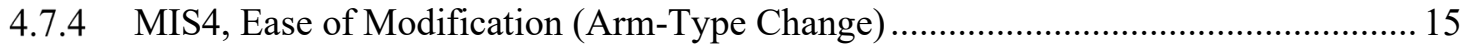

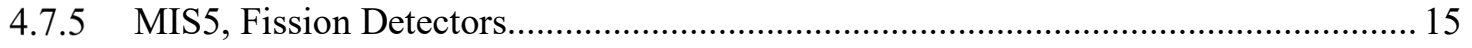

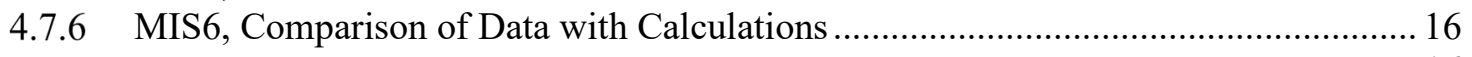

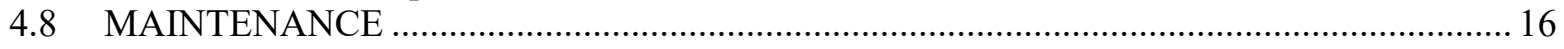




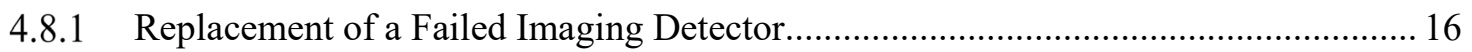

4.8.2 Replacement of Failed Constant Fraction Discriminator (CFD) ............................... 17

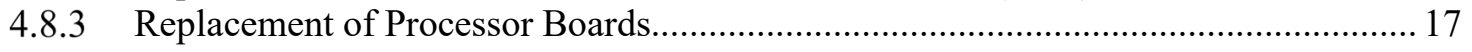

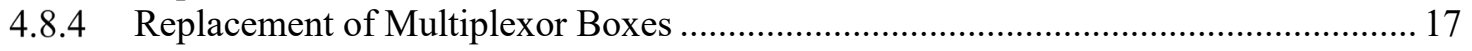

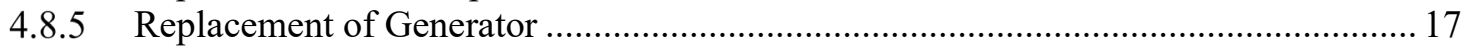

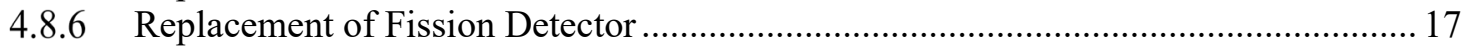

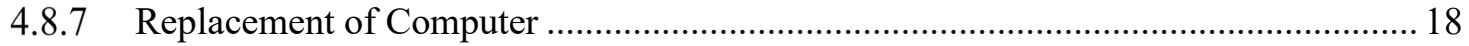

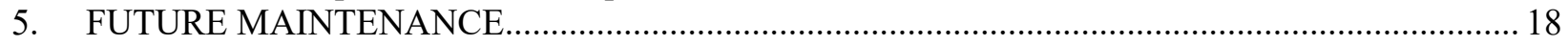

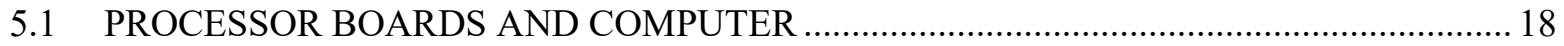

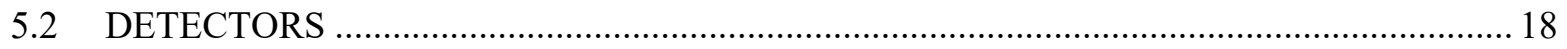

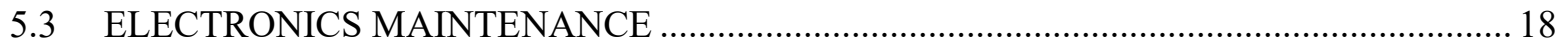

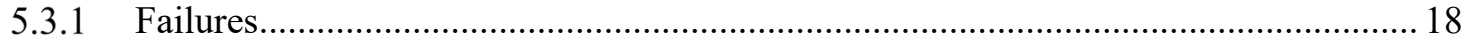

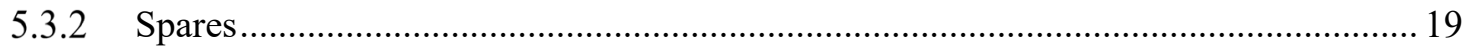

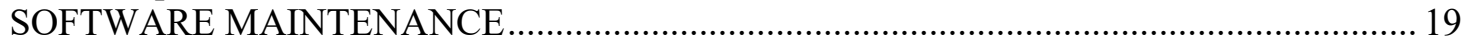

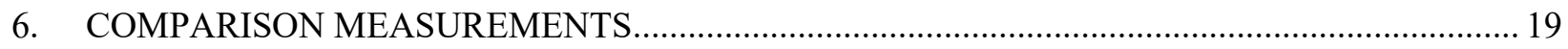

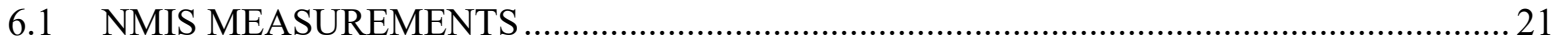

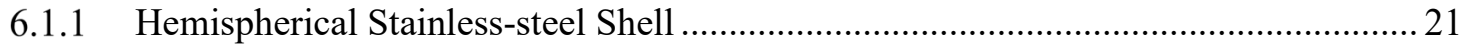

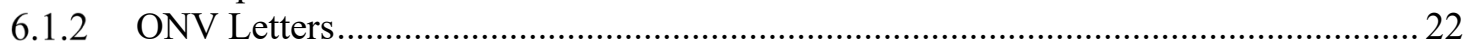

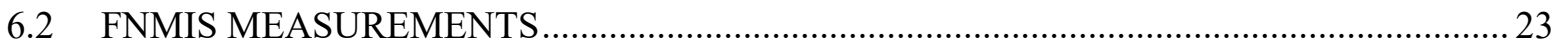

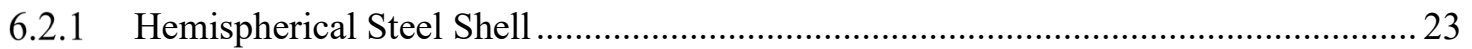

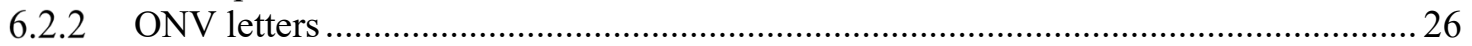

6.3 MEASUREMENT TIME DIFFERENCES AND COMPARISON …................................. 27

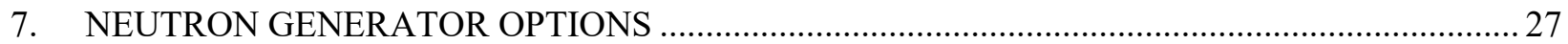

7.1 STATUS OF API DT NEUTRON GENERATORS FOR US NMIS/FNMIS ....................... 27

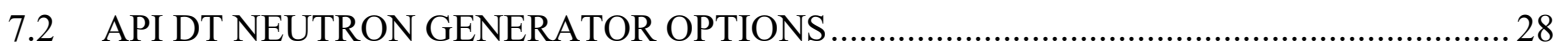

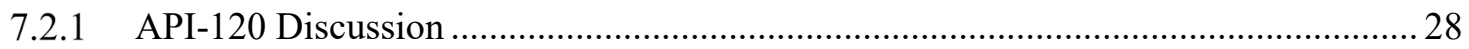

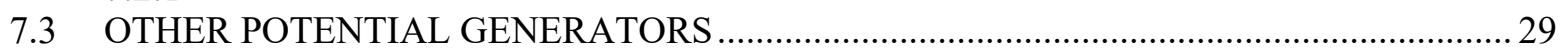

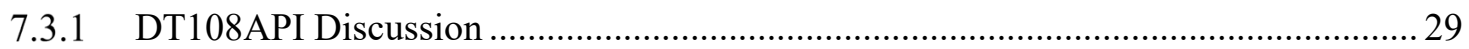

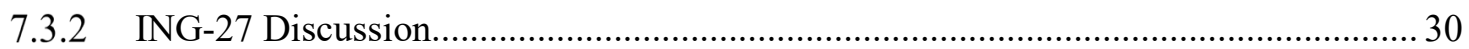

7.3.3 Other Potential Vendors for API DT Neutron Generators........................................ 30

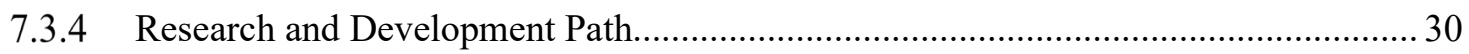

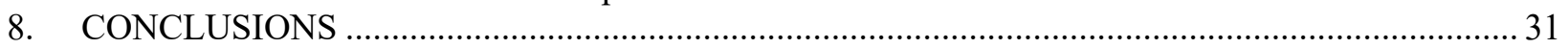

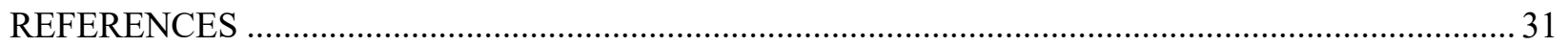




\section{LIST OF FIGURES}

Figure 1. NMIS configuration without induced fission radiation detectors............................................ 3

Figure 2. Photograph of NMIS at INL in 2010 during a fission mapping measurement........................... 3

Figure 3. NMIS electronics and data processing rack................................................................. 4

Figure 4. FNMIS configuration with one set of induced fission radiation detectors moved aside.............. 5

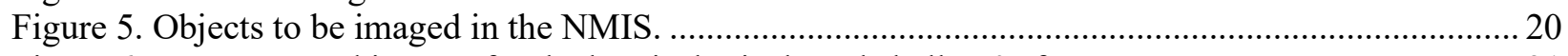

Figure 6. Reconstructed images for the hemispherical steel shell at $0^{\circ}$ from NMIS.............................. 21

Figure 7. Reconstructed images for the hemispherical steel shell at $45^{\circ}$ from NMIS............................. 21

Figure 8. Reconstructed images for the hemispherical steel shell at $90^{\circ}$ from NMIS. ............................. 22

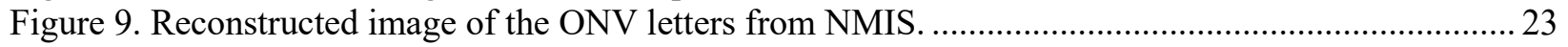

Figure 10. The hemispherical steel shells in three orientations in FNMIS. .......................................... 24

Figure 11. Reconstructed images for the hemispherical steel shell at $0^{\circ}$ from FNMIS............................25

Figure 12. Reconstructed image for the hemispherical steel shell at $45^{\circ}$ from FNMIS. .......................... 25

Figure 13. Reconstructed images for the hemispherical steel shell at $90^{\circ}$ from FNMIS..........................26

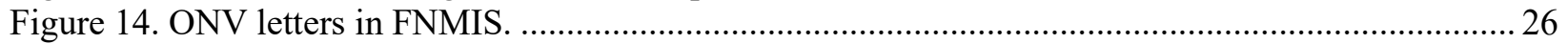

Figure 15. Reconstructed image of the ONV letters from FNMIS................................................... 27

Figure 16. Concept of the DT108API engineered with a smaller footprint............................................. 30

\section{LIST OF TABLES}

Table 1. Comparison of the advantages and disadvantages of the NMIS and FNMIS ............................. 7

Table 2. Commercial options for API DT neutron generators............................................................ 28 


\section{ACRONYMS}

$\begin{array}{ll}\text { API } & \text { associated particle imaging } \\ \text { ASIC } & \begin{array}{l}\text { application-specific integrated circuit } \\ \text { constant fraction discriminator } \\ \text { CFD }\end{array} \\ \text { DAQ } & \begin{array}{l}\text { Department of Energy } \\ \text { deuterium-tritium }\end{array} \\ \text { DOE } & \text { Fieldable Nuclear Materials Identification System } \\ \text { DT } & \text { Idaho National Laboratory } \\ \text { FNMIS } & \text { NNSA Office of Defense Nuclear Nonproliferation Research and Development } \\ \text { INL } & \text { US DOE Office of Emergency Operations } \\ \text { NA-22 } & \text { US DOE Office of Counterterrorism and Counterproliferation } \\ \text { NA-40 } & \text { nuclear materials control and accountability } \\ \text { NA-80 } & \text { Nuclear Materials Identification System } \\ \text { NMC\&A } & \text { National Nuclear Security Administration } \\ \text { NMIS } & \text { NNSA Office of Nuclear Verification } \\ \text { NNSA } & \text { Oak Ridge National Laboratory } \\ \text { ONV } & \text { photomultiplier tube } \\ \text { ORNL } & \text { time to digital converter } \\ \text { PMT } & \text { All Russian Institute of Automatics } \\ \text { TDC } & \text { All Russian Institute of Experimental Physics } \\ \text { VNIIA } & \text { All Russian Institute of Theoretical Physics } \\ \text { VNIIEF } & \text { Y-12 National Security Complex } \\ \text { VNIITF } & \end{array}$




\begin{abstract}
A comparison of the characteristics of the Nuclear Materials Identification System (NMIS) and its more fieldable version that was developed for future treaty applications, the Fieldable Nuclear Materials Identification System (FNMIS), is presented. Both systems were developed for the US Department of Energy (DOE) Office of Nuclear Verification (ONV). Under the Warhead Safety and Security Exchange Agreement, NMIS was also jointly developed with the Russian Federation. The configuration of the systems and their characteristics are described. In addition, the capabilities, advantages and disadvantages, and a comparison fast-neutron transmission imaging measurement is presented. The comparison measurements gave essentially the same results because the software and imaging apparatus have the same capabilities, with the FNMIS completing the measurements slightly faster. NMIS is an open system that is more easily modified for research applications and is not suitable for the ONV mission, and FNMIS is compatible with an information barrier, which is more useful for ONV applications.
\end{abstract}

\title{
1. INTRODUCTION
}

Oak Ridge National Laboratory (ORNL) has two nuclear materials identification systems of interest to the National Nuclear Security Administration (NNSA) Office of Nuclear Verification (ONV): (1) a development version, the Nuclear Materials Identification System (NMIS) [1], under development since the mid-1990s and (2) the Fieldable Nuclear Materials Identification System (FNMIS) [1], more recently completed in 2016. There are also two Russian versions of NMIS in the Russian Federation at the two Russian nuclear weapons design laboratories, The All Russian Institute of Experimental Physics (VNIIEF) and The All Russian Institute of Theoretical Physics (VNIITF). FNMIS is modularly designed as a test unit for potential future nuclear arms control and nonproliferation treaty activities, and NMIS is designed for research and development.

NMIS and its precursors have been used in the following applications:

- Initial measurements with secondaries at Y-12 National Security Complex (Y-12 NSC) in 1984

- Measurements with pits, secondaries, and fully assembled nuclear weapons at Pantex in 1988

- Blind testing template matching measurements with pits for the US Department of Defense, Defense Special Weapons Agency in 1997 at Los Alamos National Laboratory

- Measurements at Pantex with pits, secondaries, and fully assembled nuclear warheads in1997 for ONV

- Confirmation of inventory and receipts at the Y-12 NSC

- Isolation measurements for HEU at Y-12 NSC in 1998

- Measurements at Sandia National Laboratory, Livermore in 1999 for Y-12 NSC

- Measurements with highly enriched uranium metal (1998) and weapons-grade plutonium (2000) at VNIIEF for ONV

- Measurement at the United Kingdom Atomic Weapons Establishment with pits, secondaries, and fully assembled nuclear warheads in 2001 (Rocky Ridge 1) and in 2003 (Rocky Ridge 2) for ONV

- Passive measurements with plutonium oxide at the Euratom Joint Research Center at Ispra, Italy in 2005

- Fast-neutron imaging measurements at Y-12 NSC (initiated in 2005 for nuclear material and accountability)

- Measurements with plutonium metal (Rocky Ridge 3) at Lawrence Livermore National Laboratory in 2005 for ONV

- Passive measurements with HEU and DU metal at Y-12NSC in 2007 to 2009 for the US DOE Office of Defense Nuclear Nonproliferation Research and Development (NA-22) 
- Interrogation of air cargo at ORNL supported by Battelle Corporation (2009-2012)

- Fast-neutron imaging measurements for the US DOE Office of Emergency Operations (NA-40) in 2010 at Los Alamos National Laboratory for a counterterrorism application

- Maritime interrogation measurements in 2012 for NA-22

- The Warhead Measurement Campaign at Y-12 NSC for NA-22 in 2014

- Development of a measurement procedure for verification of dismantlement for NA-22 in 2016 at Y12 NSC

- The US DOE Office of Counterterrorism and Counterproliferation (NA-80) in 2016

These measurements provided information to support the development of FNMIS. This report compares the NMIS/FNMIS capabilities, states the advantages and disadvantages, attempts to identify all potential maintenance over the lifetime of both systems, and presents the results of a comparison fast-neutron transmission measurement.

\section{NMIS AND FNMIS CONFIGURATIONS}

There are two configurations: NMIS, under development since the 1990s by the Y-12 NSC, ONV, and NA-22; and FNMIS, developed originally by ONV and just completed in 2016 by NA-22. In 2004 fastneutron imaging capability was added to the NMIS, initially for nuclear material control and accountability (NMC\&A) applications at the Y-12 NSC. The first NMIS-type measurements with weapons components were performed in 1984 at the Y-12 NSC for NMC\&A, and the first NMIS-type measurements with fully assembled nuclear weapons ready for deployment were performed at Pantex in 1988.

\section{$2.1 \quad$ NMIS}

The configuration of NMIS is given in Figure 1, and a photograph of NMIS at Idaho National Laboratory (INL) in 2010 with the large induced fission radiation detectors installed is given in Figure 2. The imaging apparatus is located on a vertical slide for scanning an interrogated object. The apparatus allows limited lateral motion of the imaging detectors to simulate other detector locations, which increases spatial resolution. It has a rotation table to allow imaging of three-dimensional objects. The rotation table can be located closer to the source to increase magnification and reduce the measurement time for some applications. 


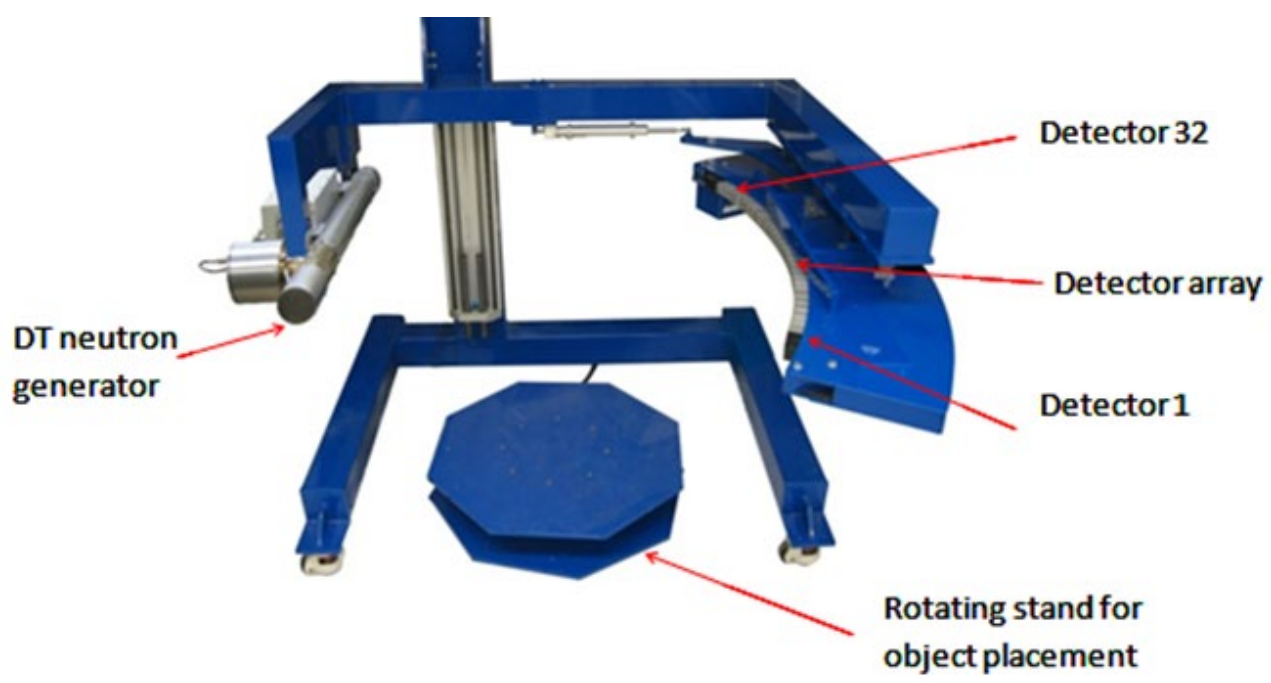

Figure 1. NMIS configuration without induced fission radiation detectors.

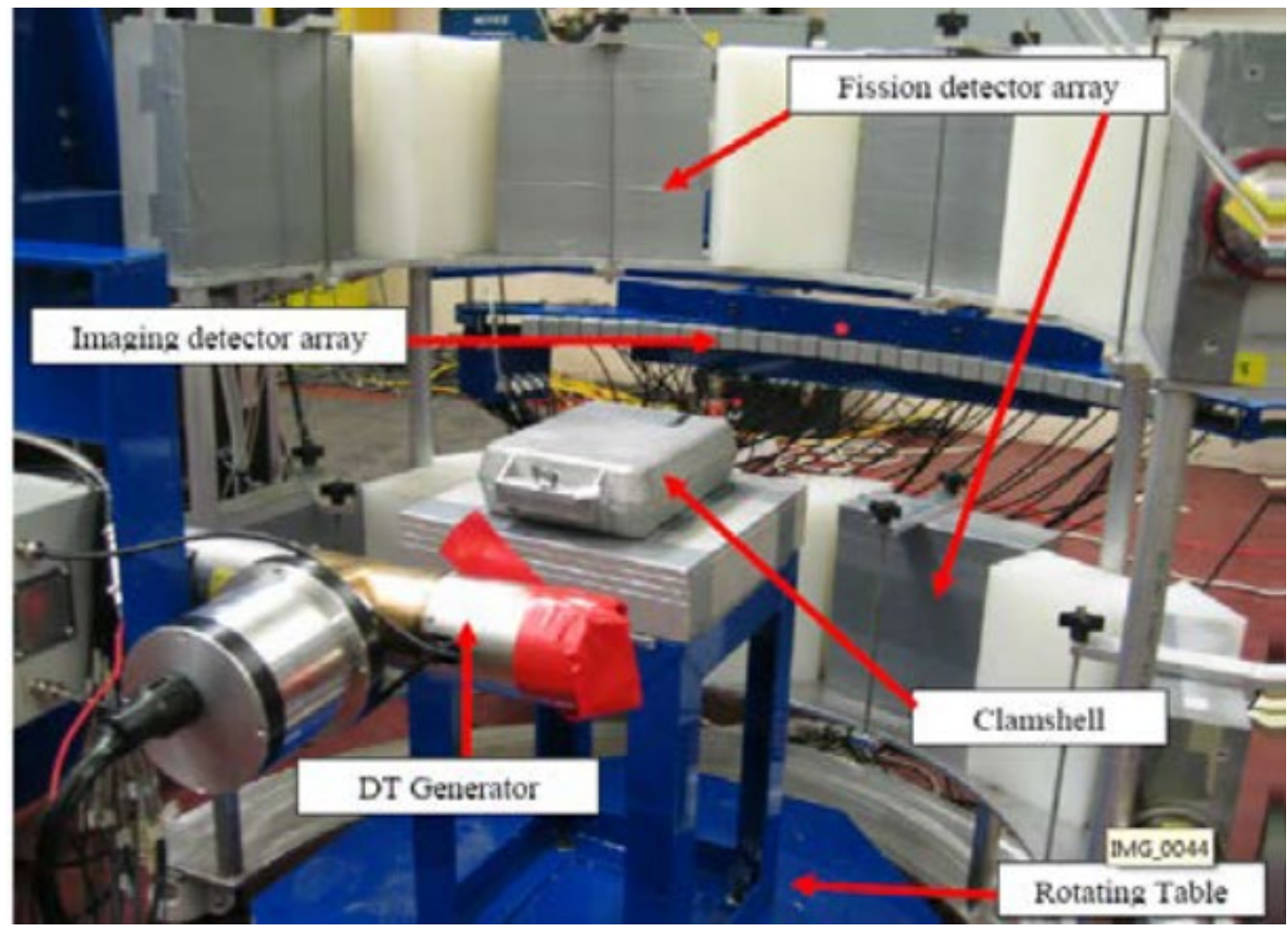

Figure 2. Photograph of NMIS at INL in 2010 during a fission mapping measurement.

NMIS usually contained 32 fast plastic scintillators in a row mounted in a $115 \mathrm{~cm}$ radius arm for imaging. The deuterium-tritium (DT) neutron generator is mounted $115 \mathrm{~cm}$ away and contains a row of alpha pixel detectors in the same plane as the imaging detectors. The induced fission radiation detectors are usually mounted between the interrogated object and the imaging detectors on a $50 \mathrm{~cm}$ radius arc with respect to the center of the interrogated object (Figure 2). They are mounted above and below the imaging detectors to allow simultaneous spatial mapping of the fission sites and fast-neutron imaging. This proximity of the 
induced fission radiation detectors to the interrogated object increased their efficiency for detection of multiplets from induced fission. A photograph of the NMIS electronics and data processing rack is given in Figure 3. It consists of three nuclear instrument module bins of analog electronics that determine the timing of the signals from the detectors and provide input to the 10 channel $1 \mathrm{GHz}$ shift registers mounted in the computer at the bottom of the rack. In each channel, the inputs can be sorted by pulse width, allowing many signals to be multiplexed into one channel. A plethora of wires route the signals appropriately to special shift registers. The processors calculate online all the correlation functions [2] between all detector pairs. There is no digitization of the signals, just timing. All set up and adjustment of voltages and detection thresholds are manual. This rack of electronics is connected to the detectors by long cables. The data acquisition user interface (data acquisition and correlation software), interactive data analysis software for off-line analysis), and imaging software had previously been used to operate the system [3]. NMIS now employs a modified version of the more user-friendly FNMIS software, which also performs additional functions.

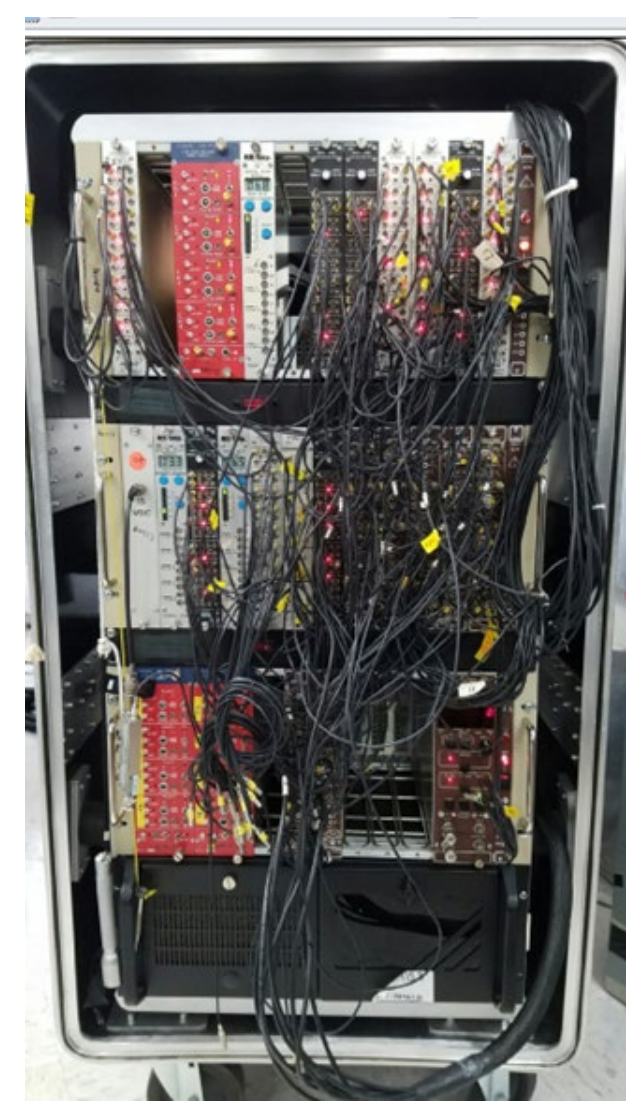

Figure 3. NMIS electronics and data processing rack.

\subsection{FNMIS}

A photograph of the FNMIS system as it will be used in a performance comparison study is given in Figure 4. FNMIS is modularly constructed with an imaging detector module, a DT generator module, a data acquisition (DAQ) module that connects the generator and imaging detector module, a rotation module, and induced fission radiation plastic scintillation detector modules. The modules can be separated for shipment, and all wiring and electronics is internal and located between modules except for the induced fission radiation detectors. The plastic scintillators for fission detection are larger for FNMIS 
but cover less solid angle than those for NMIS. The scintillator portion of the detectors is at the top and bottom of the enclosure with the photomultiplier tubes overlapping in the middle of the enclosure to conserve space. The vertical location of the fission detection modules is adjustable. Vertical positioning mechanisms that can be used to scan and object are located inside the imaging detector at DT generator modules. In addition, the imaging detector module has limited lateral motion to simulate other lateral positions of the detectors. All modules are two-man portable.

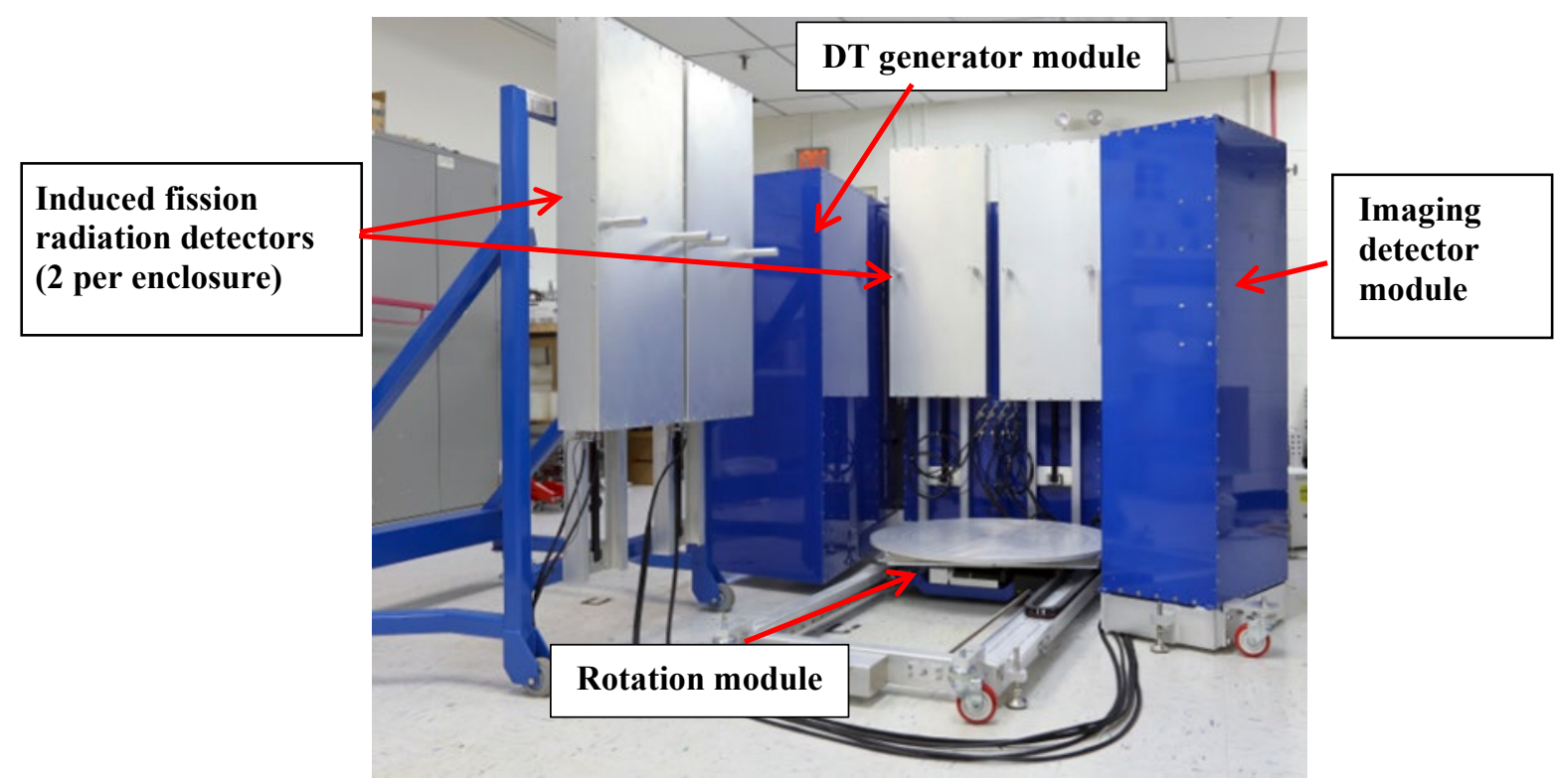

Figure 4. FNMIS configuration with one set of induced fission radiation detectors moved aside. The data acquisition module behind rotation table and fission detectors is not visible.

Two computers are located remotely to the FNMIS apparatus shown in Figure 4 - one to control the generator and one to control FNMIS. The distance separating the imager and the remote operators is effectively unlimited, including operation over Ethernet. FNMIS was designed to control the generator, but some facilities require the generator to be controlled by a separate laptop. The FNMIS user-friendly software performs all the functions that the original data acquisition user interface software did, it but is more user friendly regarding operation, display, and monitoring of the detection systems.

\section{NMIS AND FNMIS CAPABILITIES}

These two systems have quite different applications. NMIS is designed for research and development, and FNMIS is designed for use in possible future arms control and nonproliferation applications. Consequently, the FNMIS configuration is more constrained than that of the NMIS, but it is more compatible with an information barrier.

\subsection{NMIS}

NMIS is a research-oriented system that has been used in a variety of applications other than those of interest to the ONV. Fast-neutron imaging was first developed for NMC\&A applications at Y-12 NSC. NMIS has been used for counterterrorism applications, air cargo interrogation, and for stockpile stewardship applications. The source-to-imaging detector distance has been varied from 85 to $217 \mathrm{~cm}$ and can accommodate different neutron generators. This larger source-detector distance increases the magnification and allows small features of the object under interrogation to be determined. It is an open system with easy access to components, and it lends itself to upgrades. 
The NMIS originally employed a Thermo-Fisher DT neutron generator, but it was recently modified by another NA-22 program to incorporate an ING-27 generator from the All Russian Institute of Automatics (VNIIA), which reduced the measurement time by as much as a factor of five. ONV supported the development of the ING-27 generator under the Warhead Safety and Security Exchange Agreement program for the so-called "all Russian" versions of NMIS.

\section{2 $\quad$ FNMIS}

FNMIS is designed for future treaty verification applications and is a closed modular system for the evaluation of objects in containers. Its enclosed construction makes it difficult to modify as internal technologies, such as neutron generators, improve. So, what makes it useful for treaty verification impedes its use as research tool. The requirements for the FNMIS were fixed based on development of the NMIS in 2007. It presently can only accommodate an associated particle imaging DT (API-120 DT) generator from Thermo-Fisher Corporation, but its capability would be significantly improved if it was modified to accept the VNIIA ING-27 generator model or other generators with the capability of US manufacturers.

\section{ADVANTAGES AND DISADVANTAGES}

FNMIS is designed to be more user-friendly and has significant remote system monitoring and manipulation capabilities, along with significantly improved imaging visualizations. NMIS has a modified version of FNMIS software, which makes it a little easier to use and monitor the condition of the detection systems during measurements, but it cannot perform the same remote manipulation of system components as the FNMIS. Advance preparation for and performance of a recent off-site imaging campaign field-tested this modified FNMIS software in NMIS for over $50 \mathrm{~h}$ and verified the significant improvements it offers. FNMIS was designed for a specific application-future arms control treaty verification - and consequently has the advantage in such applications. NMIS was designed as a more research-oriented platform and has the advantage in research applications.

This section will outline the advantages and disadvantages as the systems as they are currently configured. These comparisons are presented in a Table 1, which is followed by discussion of each item. Because NMIS uses FNMIS software, it is referred in the table as "Modified NMIS." It will also list estimated times to replace components. With the adaptation of FNMIS software to NMIS, some of the software advantages of FNMIS have been transitioned to the current NMIS. A plus $(+)$ sign by an item is a possible advantage, and a minus (-) sign is a possible disadvantage. The biggest advantage of the NMIS system is its configuration versatility and easy access to components for replacement. The biggest advantage of the FNMIS system is the software control and monitoring of detection electronics. Both systems are limited by the obsolete processor boards that require the unsupported Windows XP operating system. Proposed improvements for various missions could easily be tested in NMIS before the costlier transition to FNMIS is made. In the later discussion of the individual items it states which system is most advantageous. The systems are compared based on the use of a Thermo-Fisher API-120 generator, which is used in the measurements [8]. Some of the advantages and disadvantages listed in Table 1 are discussed in greater detail in the following sections. 
Table 1. Comparison of the advantages and disadvantages of the NMIS and FNMIS

\begin{tabular}{|c|c|c|}
\hline Category & FNMIS & Modified NMIS \\
\hline \multicolumn{3}{|c|}{ GENERAL } \\
\hline International treaty applicability & $(+)$ Excellent & $(-)$ None \\
\hline Information barrier compatibility & $(+)$ Good & $(-)$ None \\
\hline $\begin{array}{l}\text { Research applicability and } \\
\text { versatility }\end{array}$ & (-) Limited & $(+)$ Excellent \\
\hline \multicolumn{3}{|c|}{ MECHANICAL } \\
\hline M1 Ease of shipment & $(+)$ Possible advantage & (-) Possible disadvantage \\
\hline M2 On-site assembly & $\begin{array}{l}\text { (-) Modules are mechanically } \\
\text { disassembled when shipped }\end{array}$ & ( - ) Some on-site assembly required \\
\hline $\begin{array}{l}\text { M3 Ease of system leveling and } \\
\text { alignment }\end{array}$ & $\begin{array}{l}(+) \text { Aligned automatically when } \\
\text { assembled }\end{array}$ & $\begin{array}{l}(+) \text { Prealigned before shipment } \\
\text { simplifies on site work }\end{array}$ \\
\hline M4 Ergonomics/safety & $(+)$ Closed system, safer & (-) Open system, less safe \\
\hline M5 Ergonomics/loss of power & $\begin{array}{l}(+) \text { On loss of power, imaging arm } \\
\text { stay fixed }\end{array}$ & $\begin{array}{l}(-) \text { On loss of power, imaging arm } \\
\text { descends }\end{array}$ \\
\hline M6 Ergonomics/portability & $\begin{array}{l}(+) \text { Each module two-man portable } \\
\text { modules }\end{array}$ & $\begin{array}{l}\text { (-) Forklift required for shipping, } \\
\text { wheels enable two-man mobility on } \\
\text { flat surfaces }\end{array}$ \\
\hline $\begin{array}{l}\text { M7 Operating environment (high } \\
\text { temperatures) }\end{array}$ & $\begin{array}{l}\text { (-) Enclosure requires internal } \\
\text { ventilation }\end{array}$ & $\begin{array}{l}(+) \text { Open structure is passively } \\
\text { cooled/cooler operation at higher } \\
\text { temperatures }\end{array}$ \\
\hline $\begin{array}{l}\text { M8 Operating environment (low } \\
\text { temperatures) }\end{array}$ & $\begin{array}{l}(+) \text { Enclosure may maintain operating } \\
\text { temperature. DAQ has fans }\end{array}$ & (?) Open structure lacks insulation \\
\hline M9 Temperature variations & $(+)$ Possibly more stable & (+) Acceptable stability \\
\hline M10 Generator/detector motion & $(+)$ Move independently & $(-)$ Move together \\
\hline M11 Rotation & (-) Size limits magnification & $(+)$ Larger for small objects \\
\hline M12 Source detector distance & $(-)$ Fixed at $110 \mathrm{~cm}$ & $(+)$ Variable \\
\hline
\end{tabular}

\section{ELECTRICAL}

\begin{tabular}{|c|c|c|}
\hline E1 Enclosed electronics & $(+)$ Tamper-proof & $\begin{array}{l}\text { (-) Exposed electronics rack and } \\
\text { cables easier to tamper with }\end{array}$ \\
\hline E2 Cabling & (+) Mostly internal cables & $\begin{array}{l}(-) \text { External, } 25-50 \mathrm{ft} \text {. of exposed } \\
\text { cables }\end{array}$ \\
\hline E3 Power supplies & $\begin{array}{l}\text { (-) Contains unshielded energized } \\
\text { components }\end{array}$ & $(+)$ Sealed \\
\hline E4 Electronics reliability & $(-)$ Untested & $(+)$ Analog very reliable \\
\hline E5 Electrical safety training & $\begin{array}{l}(-) \text { Qualified electrical worker } 2 \\
\text { training, cardiopulmonary } \\
\text { resuscitation, and first aid required for } \\
\text { maintenance at ORNL }\end{array}$ & $(+)$ None \\
\hline
\end{tabular}


Table 1. Comparison of the Advantages/Disadvantages of the NMIS/FNMIS (continued)

\begin{tabular}{|c|c|c|}
\hline Category & FNMIS & Modified NMIS \\
\hline \multicolumn{3}{|c|}{ SOFTWARE } \\
\hline S1 Detector settings (thresholds) & $\begin{array}{l}(+) \text { Computer control and some } \\
\text { calibrations for imaging and alpha } \\
\text { detectors thresholds }\end{array}$ & (-) No automatic calibration \\
\hline $\begin{array}{l}\text { S2 Detector settings } \\
\text { (pulse widths) }\end{array}$ & $(+)$ Computer setting of pulse widths & $\begin{array}{l}\text { (-) Manual setting of pulse widths } \\
\text { with screwdriver and oscilloscope }\end{array}$ \\
\hline $\begin{array}{l}\text { S3 Detector settings } \\
\text { (PMT voltage) }\end{array}$ & $\begin{array}{l}(+) \text { Computer controlled voltage } \\
\text { settings }\end{array}$ & (-) No voltage monitoring \\
\hline S4 General set up & (+) System set up and full monitoring & (-) Partial system monitoring \\
\hline S5 User interface & $\begin{array}{l}(+) \text { Visualizations more accurately } \\
\text { represent the hardware }\end{array}$ & $(-)$ Visualizations are representative \\
\hline S6 System set up time & $\begin{array}{l}(+) \text { Computer control and calibrations } \\
\text { decrease required time by a factor of } \\
\text { five or more }\end{array}$ & $\begin{array}{l}\text { (-) Manual adjustments with } \\
\text { screwdriver and oscilloscope are } \\
\text { more time-intensive }\end{array}$ \\
\hline \multicolumn{3}{|c|}{ MISCELLANEOUS } \\
\hline MIS1 System stability & $(+/+)$ Both equally stable & \\
\hline MIS2 Processor reliability & $(-/-)$ Both rely on limited number of in & rreplaceable processors \\
\hline $\begin{array}{l}\text { MIS3 Ease of modifications } \\
\text { (generator integration) }\end{array}$ & $\begin{array}{l}\text { (-) More difficult because of system } \\
\text { enclosure. Est. } \$ 150 \mathrm{~K} \text { for full } \\
\text { integration of ING- } 27 \text { generator and } \\
\text { imaging arm expansion }\end{array}$ & $\begin{array}{l}(+) \text { More flexible. } \$ 15 \mathrm{~K} \text { for } \\
\text { engineering and fabrication to fully } \\
\text { integrate ING- } 27 \text { generator with } \\
\text { imaging arm expansion }\end{array}$ \\
\hline $\begin{array}{l}\text { MIS4 Ease of modifications } \\
\text { (arm type change) }\end{array}$ & $\begin{array}{l}\text { (-) Enclosure complicates change in } \\
\text { arm type }\end{array}$ & $\begin{array}{l}(+) \text { Open structure facilitates change } \\
\text { in existing arm types }\end{array}$ \\
\hline MIS5 Fission detectors & (?) Larger, more flexible positioning & $\begin{array}{l}(+) \text { Smaller, more idealized } \\
\text { positioning, but are in-between object } \\
\text { and imaging detector arms }\end{array}$ \\
\hline $\begin{array}{l}\text { MIS6 Comparison of data with } \\
\text { calculations }\end{array}$ & $\begin{array}{l}\text { (?) Ambiguous determination of the } \\
\text { alpha detection rate that is needed for } \\
\text { absolute comparison with calculations }\end{array}$ & $\begin{array}{l}\text { (?) Ambiguous determination of the } \\
\text { alpha detection rate that is needed for } \\
\text { absolute comparison with calculation }\end{array}$ \\
\hline MAINTANENCE & (-) Difficult & $(+)$ Very easy \\
\hline
\end{tabular}

\subsection{FUTURE INTERNATIONAL TREATY APPLICATIONS}

In 2007, ONV decided that the NMIS capabilities were good enough for treaty verification needs and that a more fieldable system for treaty verification should be configured, in effect freezing the technology at 2007 levels. ONV initiated the configuration of a fieldable version designated as FNMIS. This system was completed in 2016. During this time ORNL made minor technical improvements to NMIS that enhanced its research capabilities. For the treaty verification applications, a concept of operations considered was a very coarse vertical scan that could mainly indicate the location of the center of the primary and the secondary, only at locations a detailed internal configuration could be determined, limiting the information acquired.

FNMIS: Designed specifically for fieldability in a potential future international treaty application.

NMIS: No applicability to future treaty application as it is a research tool not configured for fieldability. 


\section{Advantage: FNMIS}

\subsection{INFORMATION BARRIER CAPABILITY}

FNMIS: Good. FNMIS was designed specifically for compatibility with implementation of an information barrier. Total enclosure of the imaging system in modules prevents determining its condition or location with respect to an object to an outside observer, which might reveal the size of the object. In implementation, vertical motor speed and time could possibly be used to determine the location of the imaging apparatus. One possible concept of operations to avoid this is the use of random motions of the vertical adjustment before moving to its final location. This could be used to obscure the location of the imaging apparatus. Extensive software development would be required for information barrier implementation. The location of the induced fission radiation detectors might reveal information about the size of the object unless they are always used in a fixed configuration, which may not be efficient from the DAQ standpoint. The fact that the FNMIS equipment is completely enclosed in metallic boxes and that all the cables associated with the imaging system are internal prevent any detectable emission from the imaging system.

NMIS: None. NMIS was never designed for information barrier compatibility. NMIS is an open system where locations of the components are visible, and their visual position could reveal information about the object under interrogation.

\section{Advantage: FNMIS}

\subsection{RESEARCH APPLICABILITY AND VERSATILITY}

FNMIS: FNMIS is a fixed system with source-detector distance of $110 \mathrm{~cm}$. FNMIS was not designed for research. The fixed source imaging detector distance limits the ability to optimize the location of targets for the shortest measurement time. The closest the support table can be located to the source is about $50 \mathrm{~cm}$, resulting in a magnification about two, which can limit detection of small features that are not of interest to treaty verification. In most cases, modification for other applications would require rebuilding of the modules.

NMIS: NMIS is a research-oriented system that provides measurements that serve as the basis of FNMIS. NMIS can easily accommodate a wider variety of neutron generators and target objects efficiently for a wider variety of applications. Neutron source-imaging detector distances between 85 and $217 \mathrm{~cm}$ have been used. Larger distances between the source and detector increase magnification but reduce the efficiency. This can be partially offset by increasing the number of detectors. If fact, NMIS now has an application that increases the number of imaging detectors to 62 on a $217-\mathrm{cm}$ imaging arc.

\section{Advantage: NMIS}

\subsection{MECHANICAL}

\subsubsection{M1, East of Shipment}

FNMIS: FNMIS modules are assumed to be individually crated for shipment. The power and connections between the cabinets are disconnected. Fission counter cables are disconnected at one end and coiled up. The imaging detector and generator modules are disconnected from the DAQ. Three modules are crated, and the steel frame is forklifted onto the shipping vehicle. Two-man portable modules are loaded into shipping boxes, and the boxes are then forklifted and lashed down in the truck. The control cables to control computer are coiled up and shipped with the control computer. In some cases, the DT generator 
may have to be shipped out of its module. The use of $\mathrm{SF}_{6}$ usually means that the generator cannot be shipped in the DT generator module, making shipping more complicated. For the protection of the generator during shipment, it would be best to package and ship them separately.

An alternative is to ship the imaging detector, DAQ, and DT generator modules assembled on the steel frame. Rotating tables and fission detector modules would be packaged separately. This alternative would simplify shipping and set up.

NMIS: The NMIS imaging apparatus needs to be crated. Power is disconnected from the scanning motors and instrumentation rack. The cables between the instrumentation rack and the imager and fission detectors are disconnected at the imager and are coiled up and placed in the back of the instrumentation rack. The covers for the front and back of the instrumentation racks are put on. The cables for the imager motor controls are coiled up and shipped with the control computer. The measurement apparatus is crated. The instrumentation rack with covers is loaded. The generator and the NMIS imaging detector apparatus are shipped separately to minimize possible damage during shipment. NMIS imaging detectors are shipped with the NMIS imaging apparatus.

\section{Advantage: Unclear}

\subsubsection{M2, On-site Set up}

All items are assumed to be removed from shipping crates prior to set up. The leveling time is the same for both systems.

FNMIS: In principle FNMIS should be faster, but ORNL currently has not performed a demonstration. If three main modules were shipped with the generator installed in its module on the frame, the mechanical set up time could be less than $1 \mathrm{~h}$ ORNL has no experience in setting up the system with the modules shipped separately. A future exercise to test this would be beneficial. This exercise would involve shipping the system off-site and reassembling it for a measurement. Methods to simplify the installation of the generator need to be developed.

NMIS: Experience has been about $2 \mathrm{~h}$ or less for mechanical assembly

\section{Advantage: FNMIS}

\subsubsection{M3, Alignment}

FNMIS: Three main modules are shipped on the frame on which they are aligned. When unloaded, the system must be leveled, which takes about 15 min.

NMIS: Alignment, including leveling of the imaging apparatus, mounting the generator, and aligning the detectors and the generator the same distance from the floor takes $45 \mathrm{~min}$ (measured). The alignment process uses a laser leveling system for final adjustment. If the generator and imaging detectors are prealigned before shipment, the time could be reduced to about $20 \mathrm{~min}$.

\section{Advantage: FNMIS}

\subsubsection{M4, Ergonomics/Safety}

FNMIS: When all the modules are closed, the FNMIS is safer. Electrical components are inside the cabinets. 
NMIS: NMIS is an open system and is less safe. Proximity to mechanical motion must be avoided. Electrical components are exterior but shielded within their own commercial housings. Cables could present a tripping hazard.

\section{Advantage: FNMIS}

\subsubsection{M5, Ergonomics/Loss of Power}

FNMIS: In the event of a loss of power to the vertical motor, the generator and imaging detectors configuration remains at the original height. This is an advantage for restarting the system.

NMIS: Loss of power to the vertical motor results in the imaging detectors and DT generator moving down. Shims prevent the imaging and generator arm from going to the bottom. Position calibration is lost and must be reestablished.

\section{ADVANTAGE: FNMIS}

\subsubsection{M6, Ergonomics/Portability}

FNMIS: Each module is two-man portable and can be placed on the underlying frame.

NMIS: A forklift may be required to ship the imaging mechanical apparatus, but wheels enable two-man mobility on flat surfaces. The instrumentation rack is enclosed for shipment, but it is on wheels at the location. The NMIS imaging apparatus was rolled out of a facility and back into a truck on a recent trip.

Advantage: Unclear

\subsubsection{M7, Operating Environment (High Temperatures)}

FNMIS: The enclosure is actively ventilated with fans. The computer uses internal fan cooling.

NMIS: NMIS is an open structure and is passively cooled, producing cooler operations at higher temperatures.

\section{Advantage: Unclear}

\subsubsection{M8, Operating Environment (Low Temperatures)}

FNMIS: The FNMIS enclosure requires internal ventilation with fans and could insulate electronics in cold environments.

NMIS: NMIS is an open structure is passively cooled, producing cooler operations at higher temperatures. Use of $400 \mathrm{~W}$ nuclear instrument module bins provide a heat source.

\section{Advantage: Unclear}

\subsubsection{M9, Temperature Variations}

FNMIS: FNMIS may be more stable than NMIS.

NMIS: Electronics settings could be sensitive to temperature, but previous operation in a facility where the temperature varied by $14^{\circ} \mathrm{F}$ was not a problem. NMIS stability to temperature is acceptable. 


\section{Advantage: Unclear}

\subsubsection{M10, Generator/Detector Motion}

FNMIS: The generator and the imaging detector arm move independently. The independent motion allows easier measurement of vertical profile of neutron beams.

NMIS: The generator and the imaging detector arm are rigidly coupled together and move simultaneously to the same height. Three separate $2 \times 2 \times 2$-inch plastic scintillators are fixed vertically independent of the imaging arm and are used during vertical scanning of the generator. Plots of the response as a function of the vertical position are used to determine if the fan beam of neutrons is horizontal and at the correct vertical location. The set up and use of these extra detectors is an additional operation that is not needed in FNMIS.

\section{Advantage: FNMIS}

\subsubsection{M11, Rotation}

FNMIS: The size of rotation stage limits magnification during tomography. The center of rotation is about $50 \mathrm{~cm}$ from the source, so the magnification is limited to about 2.3. FNMIS is designed for items in the drums.

NMIS: The rotation table can be closer to the source, and this allows larger magnification, reducing measurement time.

\section{Advantage: NMIS}

\subsubsection{M12, Source-to-Detector Distance}

FNMIS: The distance is limited to $110 \mathrm{~cm}$, which limits the size of the object.

NMIS: Source detector distances between 85 and $217 \mathrm{~cm}$ have been used. Much larger objects can be measured, as can smaller objects with larger magnification.

\section{Advantage: NMIS}

\subsection{ELECTRICAL}

\subsubsection{E1, Enclosed Electronics}

FNMIS: Once the modules are enclosed, the electronics are tamper-proof. One cannot miswire the electronics or any other cables. This is effective and necessary for future treaty applications.

NMIS: The NMIS electronics instrumentation rack cables are easily miswired by an operator in a hurry who makes a mistake or by someone trying to sabotage the system. This has not been a problem in all deployments because each cable was marked, and the system was in a friendly environment.

\section{Advantage: FNMIS}




\subsubsection{E2, Cabling}

FNMIS: Most cables are internal except for the induced fission radiation detectors. Those passing between modules are not accessible.

NMIS: All 96 cables for the imaging apparatus and fission detectors are visible and accessible. Twenty to fifty feet of cable is used between the detectors and the between electronics instrumentation and data processing. This limits the standoff distance of the electronics rack and poses a tripping hazard. If adjustment of the electronics is required with the generator turned on, the operator must enter a radiation field of a few millirem per hour.

\section{Advantage: FNMIS}

\subsubsection{E3, Power Supplies}

FNMIS: FNMIS contains unshielded energized components inside the sealed cabinets. This is not a problem unless the cabinets are open for maintenance that requires the module be energized.

NMIS: All power supplies are not exposed and are self-contained units.

\section{Advantage: NMIS}

\subsubsection{E4, Electronics Reliability}

FNMIS: This system was in use for a very short time, so a determination about its reliability cannot be made. One imaging detector, an application-specific integrated circuit (ASIC) CFD, failed when one module was moved in 2014 to Y-12 for a measurement. One Windows XP computer failed in August 2017.

NMIS: In use for decades with some nuclear instrument module electronic failures, imaging detector failures, and power supply failures.

Note: The most common failure over the years has been the imaging detectors themselves, which is a common issue for both systems.

\section{Advantage: UNCLEAR}

\subsubsection{E5, Electrical Safety Training}

FNMIS: Inside the cabinets there is the potential for worker exposure to voltage and current. When performing maintenance with the power on, additional training above the basic electrical worker training is required, such as qualified electrical worker 2, cardiopulmonary resuscitation and first aid, to access inside the cabinets with the power on. With the power off, no specialized training is required.

NMIS: No exposed voltage and current. Only basic electrical worker training is required.

\section{Advantage: NMIS}




\subsection{SOFTWARE}

\subsubsection{S1, Detector Settings (Thresholds)}

FNMIS: Computer control makes it easy to set the detector voltages and thresholds remotely and check the settings during operation. These settings can also be changed remotely during operation.

NMIS: Setting thresholds is done manually with a screwdriver and oscilloscope at the electronics rack. To reduce the neutron dose, the electronics rack is located further away from the generator by running long cables between the detectors and the electronics rack.

\section{Advantage: FNMIS}

\subsubsection{S2, Detector Settings (Pulse Widths)}

FNMIS: Computer control makes it easy to set the detector voltages and thresholds remotely and check the settings during operation. These settings can also be changed remotely during operation.

NMIS: Pulse widths are set manually with a screwdriver and oscilloscope at the electronics rack.

\section{Advantage: FNMIS}

\subsubsection{S3, Detector Settings (PMT Voltage)}

FNMIS: Computer control makes it easy to remotely set and check the settings. The settings can progressively ramp up the voltage to detector elements and automatically increase to the final settings. This also happens when the voltage is turned off. This potentially limits wear and improves reliability.

NMIS: Voltage is set manually with a screwdriver and oscilloscope at the electronics rack.

\section{Advantage: FNMIS}

\subsubsection{S4, General Set up}

FNMIS: Computer control enables full system monitoring and remote setting adjustments.

NMIS: Partial system monitoring

\section{Advantage: FNMIS}

\subsubsection{S5, User Interface}

FNMIS: Visualizations displayed on the control console more accurately represent the hardware configuration.

NMIS: Adaptation of the FNMIS software to NMIS does not provide a complete display of the system's status, particularly the location of the generator but it reliably shows the measurement progress and results.

\section{Advantage: FNMIS}




\subsubsection{System Set up Time}

FNMIS: Computer control and calibrations decrease required initial set up time by a factor of three or more.

NMIS: Manual adjustments with screwdriver and oscilloscope are more time-intensive.

\section{Advantage: FNMIS}

\subsection{MISCELLANEOUS}

\subsubsection{MIS1, System Stability}

FNMIS: This system could be more stable and requires further testing.

NMIS: This system has never had any stability problems.

\section{Advantage: Unclear}

\subsubsection{MIS2, Processor Reliability}

FNMIS: This system uses the same processor as NMIS.

NMIS: This system uses the same processor as FNMIS.

\section{Advantage: Neither}

\subsubsection{MIS3, Ease of Modification (Generator Integration)}

FNMIS: It is more difficult to change the generator type because of the system enclosure. To fully integrate the ING-27 generator and imaging arm expansion, it is estimated to cost $\sim \$ 150 \mathrm{~K}$. The enclosures limit changes and must be modified because FNMIS was not designed for flexibility.

NMIS: NMIS is more flexible, and to fully integrate the ING-27 generator and imaging arm expansion, engineering and fabrication is estimated to cost $\$ 15 \mathrm{~K}$ (from another NNSA program). The lack of constraint of the enclosures increases flexibility.

\section{Advantage: NMIS}

\subsubsection{MIS4, Ease of Modification (Arm-Type Change)}

FNMIS: Difficult because of enclosure

NMIS: Easily changed

\section{Advantage: NMIS}

\subsubsection{MIS5, Fission Detectors}

FNMIS: FNMIS uses larger induced fission radiation detectors. There is flexibility regarding where they are located, but they would be further away. FNMIS could do fission mapping for larger objects. The count rates at the present location are too high for maximum operation of the API-120 at $4 \times 10^{7} \mathrm{n} / \mathrm{s}$. For 
active fission mapping measurements, they could be relocated behind the imaging detectors. Their present location is ideal for passive measurements with fissile material with inherent sources.

NMIS: The induced fission radiation detectors are slightly smaller and can be positioned more ideally. They are located between object and imaging detector arms, but the location limits the size of objects for fission mapping. These detectors usually have been located on an arc about $50 \mathrm{~cm}$ from the center of the interrogated object. Thus, they are more efficient for smaller objects. They have usually been located above and below the vertical center of the object, so they do not interfere with a simultaneous imaging measurement at the vertical center of an object. For large objects, detectors would be further away and less efficient.

\section{Advantage: UNCERTAIN}

\subsubsection{MIS6, Comparison of Data with Calculations}

FNMIS: Ambiguous determination of the alpha pulse rates in the API-120 generator introduces uncertainty in the comparison of calculations with the API-120 generator. This does not affect any imaging measurements where ratios of detector responses are used. Any comparison involving an absolute comparison, such as calculation the number of doubles in a fission mapping measurement, will have this uncertainty.

NMIS: Ambiguous determination of the alpha pulse rates in the API-120 generator introduces uncertainty in the comparison of calculations with the API-120 generator. Using the ING-27 in NMIS removes this uncertainty.

\section{Advantage: NMIS with ING-27 generator until ING-27 integration with FNMIS. After integration,} they are equivalent.

\subsection{MAINTENANCE}

Maintenance is concerned mainly with the ease of replacement of the components. The time it takes to replace a component was estimated by ORNL (Sections 4.8.1-4.8.7). One time-consuming task for FNMIS maintenance is the removal and replacement of the sides or back of the modules, some of which have 75 screws. To derive these time estimates, Chuck Britton, Thad Thompson, J. P. Jones, Nance Ericson, and others were consulted. Of course, the same component must fail in both systems to be compared. The times given for replacement of components are estimated and some have been measured. For FNMIS the availability of an electric-powered screwdriver is assumed. With repetitive training, it is expected that many of these times could be reduced.

\subsubsection{Replacement of a Failed Imaging Detector}

FNMIS: The back of the cabinet must be removed -

Removal of the detector ------- 5 min

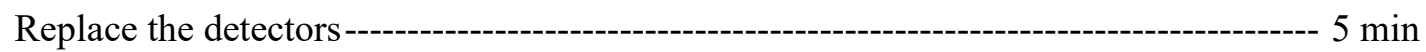

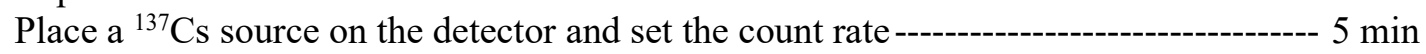

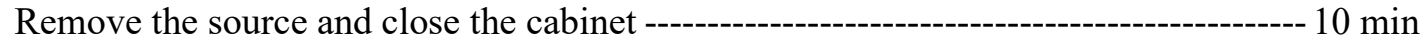

Total Time ------------------------------------------------------------------------------------ 35 min

NMIS: Remove and replace the detector -------------------------- 5 min

Place a ${ }^{137} \mathrm{Cs}$ source on the detector and set the count rate---------------- $10 \mathrm{~min}$

Total Time 


\subsubsection{Replacement of Failed Constant Fraction Discriminator (CFD)}

FNMIS: Removal of the back of the cabinet --

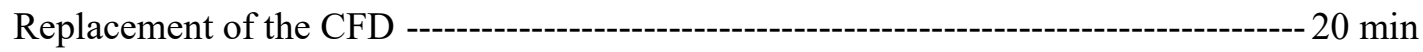

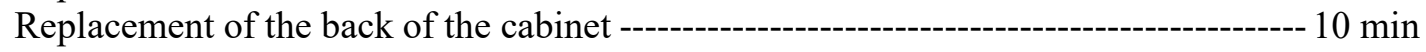

Total time --

NMIS: Remove of ORTEC CFD -

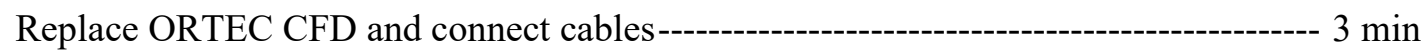

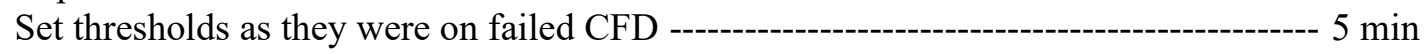

Total time ------------------------------------------------------------------------------------- 10 min

\subsubsection{Replacement of Processor Boards}

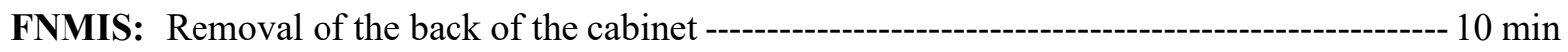

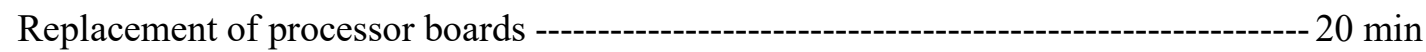

Replacement of the back of the cabinet ---

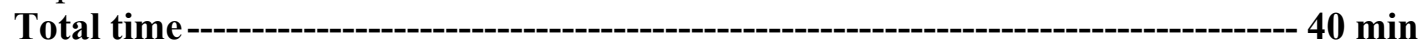

NMIS: Disconnect cables and sliding computer out of rack ----------- $10 \mathrm{~min}$

Replacement of processor boards -------

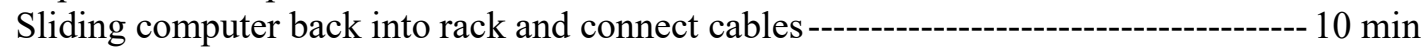

Total time --------- 40 min

\subsubsection{Replacement of Multiplexor Boxes}

FNMIS: Removal of the back of the cabinet -

Replacement of multiplexor box ---o-- 60 min

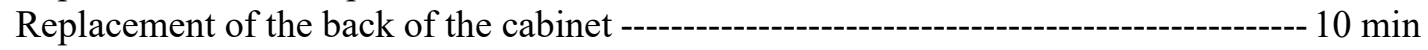

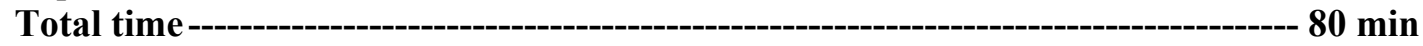

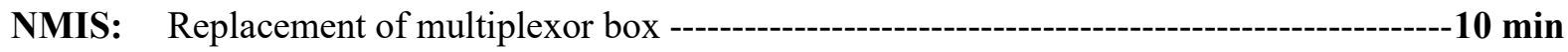

\subsubsection{Replacement of Generator}

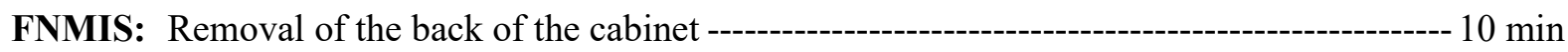

Remove the generator--------------- $30 \mathrm{~min}$

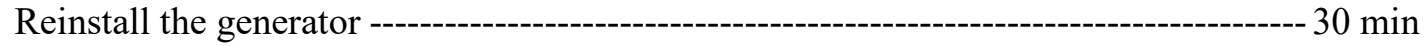

Replacement of the back of the cabinet ------

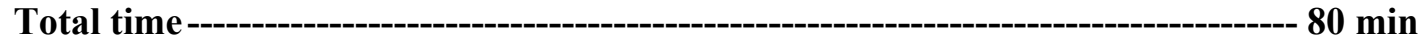

NMIS: Removal of generator ---

Reinstall the generator (measured) ---

Total time ----------------------------------------------------------------------------------------- 35 min

\subsubsection{Replacement of Fission Detector}

FNMIS: Removal of detector module ------------- 10 min

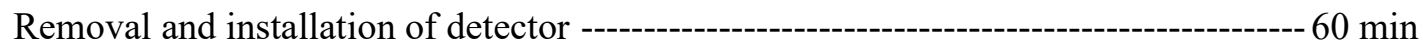

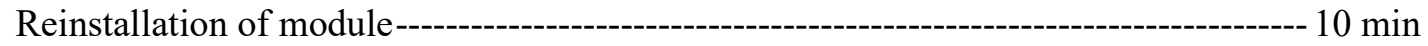

Total time --

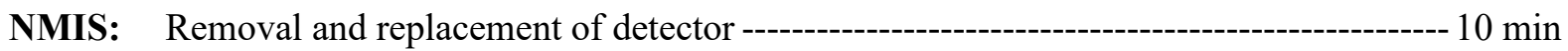




\subsubsection{Replacement of Computer}

FNMIS: Removal of back of cabinet --- 10 min

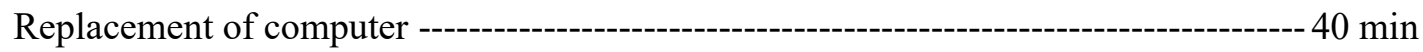

Replacement of back of cabinet --- $10 \mathrm{~min}$

Total time ---------- 60 min

NMIS: Disconnect processor board cables------------------------------------------------------------ 2 min

Replacement of computer --------------- 15 min

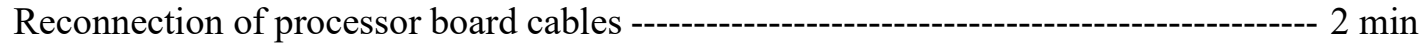

Total time --------------------------------------------------------------------------------------------- 19 min

\section{FUTURE MAINTENANCE}

\subsection{PROCESSOR BOARDS AND COMPUTER}

Both systems rely on processor boards that have a limited lifetime and cannot be reproduced cheaply. Eight pairs of processor boards are on hand. They are 10-channel $1 \mathrm{GHz}$ shift registers specially designed and fabricated by ORNL. Each processor card contains five input channels, so each system has two processor boards installed in computers running the unsupported Windows XP operating system. The signals from each detector with different pulse widths set by the constant fraction discriminators are input to multiplexor circuits, which send different width signals to the processor board channels. The software identifies the individual detector signals in each input channel of the processor by their pulse width and processes them accordingly. Computers that use these processor boards are incompatible with modern operating systems and associated software developed for them, which limits the transition to smaller, more efficient data acquisition and analysis modules. The size of the $1 \mathrm{GHz}$ processor boards precludes their use in small computers. In July 2017, the FNMIS computer had to be replaced.

If NMIS is only required to process an event's time-of-arrival, then the NMIS boards should be replaced with a commercially available time to digital converter (TDC) board. ORNL has identified the CAEN V1190A TDC board as a suitable solution and has tested successfully the V1190B TDC board, a similar board with fewer channels. This option provides a near-term solution to replacing the NMIS boards. However, the NMIS DAQ will need to also process pulse heights to mitigate any future supply issues with API DT neutron generators. As part of a current NA-221 project, ORNL is partnering with Lawrence Livermore National Laboratory to develop a DAQ solution using commercially available electronics that can process both the pulse height and time-of-arrival of alpha detector events. ORNL can report later the development and its applicability to FNMIS.

\subsection{DETECTORS}

The failure rate of imaging detectors is greater than expected, and ORNL is considering replacing the photomultiplier tubes (PMTs) with silicon photomultiplier tubes (SiPMs), which are more rugged and should have longer life.

\subsection{ELECTRONICS MAINTENANCE}

\subsubsection{Failures}

The primary failure mechanism has been found to be the result of two root causes. The first is the ASIC design. The ASIC works very well from a functional standpoint, but there appears to be a reliability issue associated with what the semiconductor industry calls "antenna rules." Many steps in semiconductor processing involve lithography and ion implantation. During these steps, the interconnecting metal lines 
that connect transistors together receive doses of charge (electrons) that can collect on the capacitance created between the metal and the substrate of the ASIC or on the capacitance of the actual transistors themselves. This charge accumulation can change the voltage on the capacitance and potentially cause damage to the transistor devices, particularly the gate oxide. It is thought the gradual degradation of some of the ASICs is due to this very issue even though most, but not necessarily all, of the rules were followed. This issue could be corrected in another fabrication round of the devices.

The second failure, much more easily corrected, has been that of cable connectors. Many connections are inside the cabinet, and some have been found to be unreliable because of vibration and changing temperatures. Most, if not all, of these have been repaired or replaced, but some may remain and could fail at a future time.

\subsubsection{Spares}

There is a total of 64 CFD boards in each FNMIS, six CFD motherboards, various high-voltage supply boards, and other miscellaneous boards. Few spare boards are currently in stock because almost all were used at various stages of development. There are no spare multiplexor box boards. It would cost $\$ 50 \mathrm{~K}-$ $\$ 75 \mathrm{~K}$ to acquire adequate spares for future operations.

\section{SOFTWARE MAINTENANCE}

To perform the comparison measurements with FNMIS, some slight software modifications were made by Thad Thompson of CADRE 5 Corp. A problem with rotational motion occurred when approaching a given angle from one direction, which caused the table to stop $0.2^{\circ}-0.3^{\circ}$ above the demand setting. Rotation in the reverse direction was not a problem. With the limited experience, it is difficult to project life cycle maintenance costs for FNMIS.

\section{COMPARISON MEASUREMENTS}

The performance of NMIS and FNMIS for fast-transmission neutron imaging are compared. Originally, fission mapping measurements were going to be compared, but the location of the induced fission radiation detector in the FNMIS precluded these measurements because of the high-count rates in the fission radiation detectors with the operation of the generator (2.6 million per second) at the same output as for the NMIS measurements. The initial location of the fission detectors in FNMIS was based on taking passive measurements with plutonium where high efficiency is required. The NMIS fission mapping measurements that were completed before the FNMIS measurements were attempted are not presented because many of them are already in the literature and no comparison to FNMIS could be made. Many previous successful FNMIS fission mapping measurements were performed during the development of FNMIS. These measurements are the first set of measurements to test FNMIS in its completed state by comparing it to the same measurement with NMIS. Although many objects were measured on both systems, a one-to-one comparison had not been performed, with the same object or generator operating conditions. These measurements were performed at ORNL and used to assess, for the first time, how well the FNMIS meets some of its design requirements. The requirements for FNMIS were (1) increased portability, assembly, and disassembly over NMIS; (2) improved measurement set up performance over NMIS; and (3) the same or better image quality. This effort mainly addressed the second and third requirements. Some requirements may need further testing beyond this project and will be identified in a long-term plan.

Fast-neutron transmission imaging measurements with both systems are compared. Previous work demonstrated the three-dimensional imaging capability of NMIS and FNMIS. The measurements performed here included a configuration of steel letters and a hemispherical steel shell. The letters had 
vertical symmetry but no rotational symmetry and therefore were a test of the tomographic reconstruction capability. In contrast, the hemispherical shell had neither rotational symmetry nor vertical symmetry and were therefore a test of the three-dimensional radiograph capability. The configuration of the letters has been imaged before using a variety of generator and detector parameters but has not provided a straightforward comparison of NMIS and FNMIS performance,

The data acquisition times were the same for these measurements. The imaging detector efficiencies in both systems were initially set to the same by using a $1 \mu \mathrm{Ci}{ }^{137} \mathrm{Cs}$ source on top of each imaging detector and adjusting the count rates to 5\% within and between each system. This could not easily be done with FNMIS because of the required electrical training needed to do this. The ${ }^{137} \mathrm{Cs}$ source was used for only four of the detectors in FNMIS. With no sources present, the CFD thresholds were adjusted until the background count rates were nearly the same. For the final check to match the detectors with the NMIS measurements, the neutron generator was turned on to the same voltage $(90 \mathrm{KV})$ and beam current $(50 \mu \mathrm{A})$. The alpha pixel count rates were adjusted to match those in the NMIS measurement. The correlated counts in the imaging detectors were adjusted to the count rates for the NMIS measurements.

The objects that were imaged are shown in Figure 5. On the left is a two-dimensional object consisting of letters "O," "N," and "V." The "O" is made of depleted uranium, the "N" is steel, and the "V" is plastic (polylactic acid). Both transmission imaging and fission mapping measurements were performed. The induced fission mapping measurements should indicate the presence of induced fissions in the depleted uranium. The object was centered vertically between upper and lower fission detector rows. The other object, on the right, is a stainless-steel hemispherical shell. The hemispherical shell was scanned vertically in three different orientations by rotating the shell $45^{\circ}$ and $90^{\circ}$ from its position in Figure 5 .

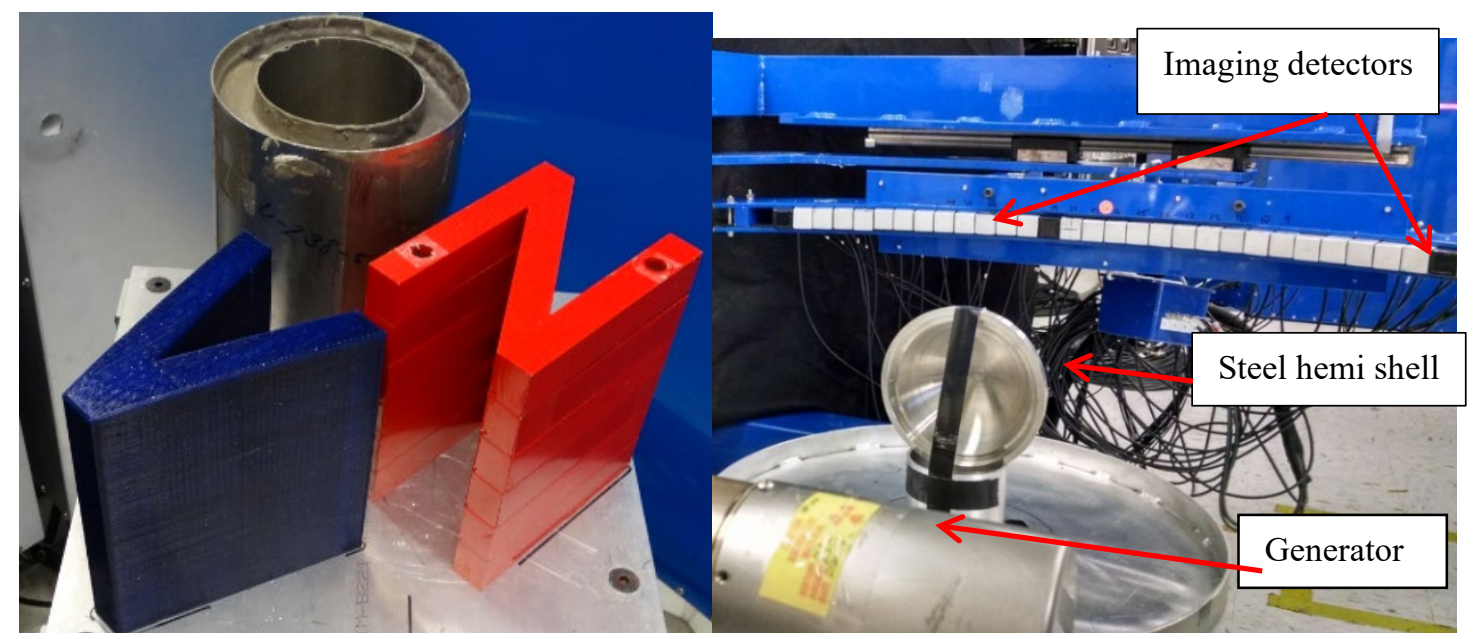

Figure 5. Objects to be imaged in the NMIS. (Left) Letters for two-dimensional object. (Right) Hemispherical steel shell.

The letters were measured at a single height near the centerline of the object and had to be rotated because there was not cylindrical symmetry. During actual testing, the letters were rearranged differently from Figure 5, with the "V" located in front of the "O" and the "N." Rotating the object 60 times (or about $6^{\circ}$ per image) should be sufficient and has been used in the past for this type of object. Only a single height was measured to conserve generator operation hours. The configuration of the induced fission radiation detectors in the NMIS system is shown in Figure 2. The FNMIS configuration is like that shown in Figure 4 except the two sets of fission detectors to the left in the photo are rotated to be $180^{\circ}$ from those beyond the rotation table. Although the object to be measured can be located closer to the source (thus increased magnification) in NMIS, the object is located at the same distance from the source for the sake of comparison of both systems. 


\subsection{NMIS MEASUREMENTS}

\subsubsection{Hemispherical Stainless-steel Shell}

The stainless-steel hemispherical shell was measured in two other orientations, in addition to the one shown in Figure 5, by rotating it $45^{\circ}$ and $90^{\circ}$. Only a few rotations were performed to save generator operation time. Each of the three imaging measurements was performed with the API generator \#103 operating at $90 \mathrm{KV}$ and a $50 \mu \mathrm{A}$ beam current, with six lateral positions of the imaging detector (subsamples), $102 \mathrm{~s}$ of data for each subsample, and height steps of $1.0 \mathrm{~cm}$. The distance between the source and the equatorial plane of the hemispherical shell at the orientation shown in Figure 5 was $50 \mathrm{~cm}$. The transmission image reconstructions are plotted in Figure 6 to Figure 8.

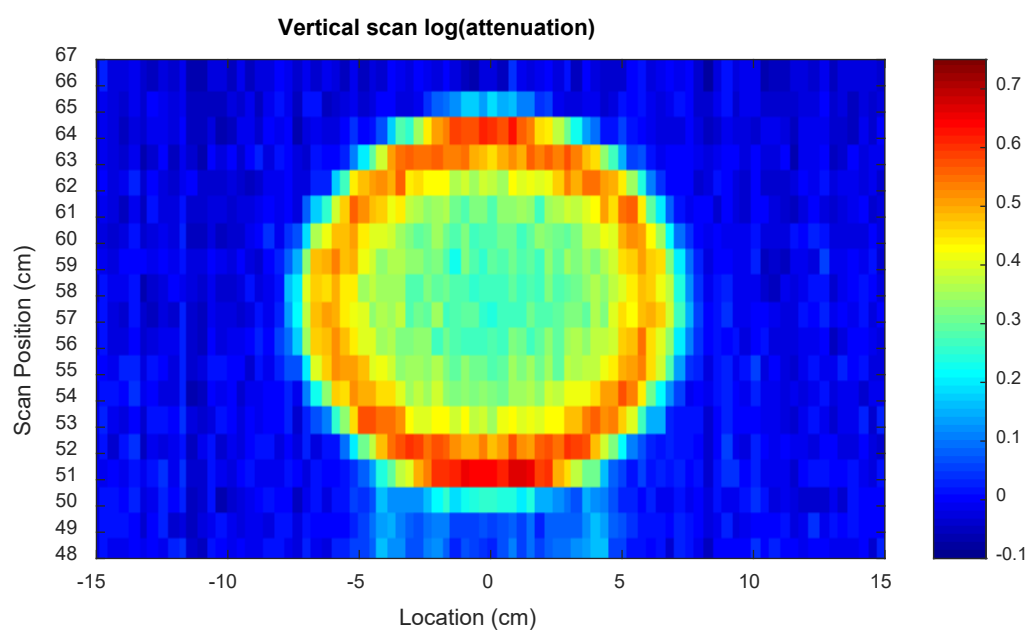

Figure 6. Reconstructed images for the hemispherical steel shell at $0^{\circ}$ from NMIS.

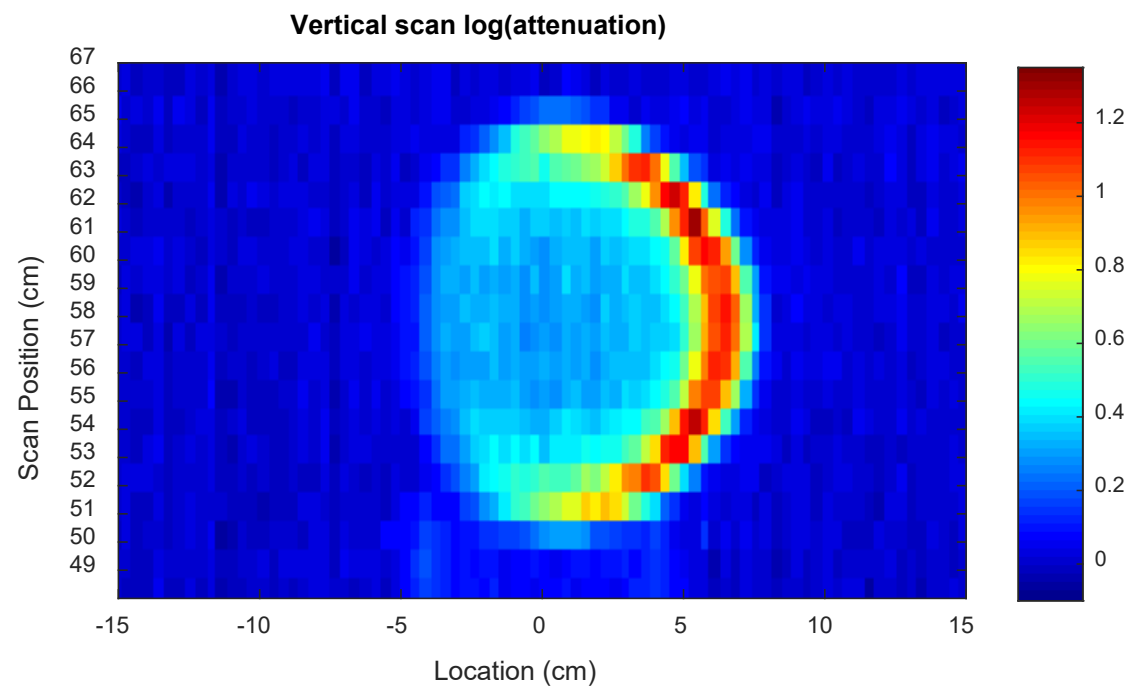

Figure 7. Reconstructed images for the hemispherical steel shell at $45^{\circ}$ from NMIS. 


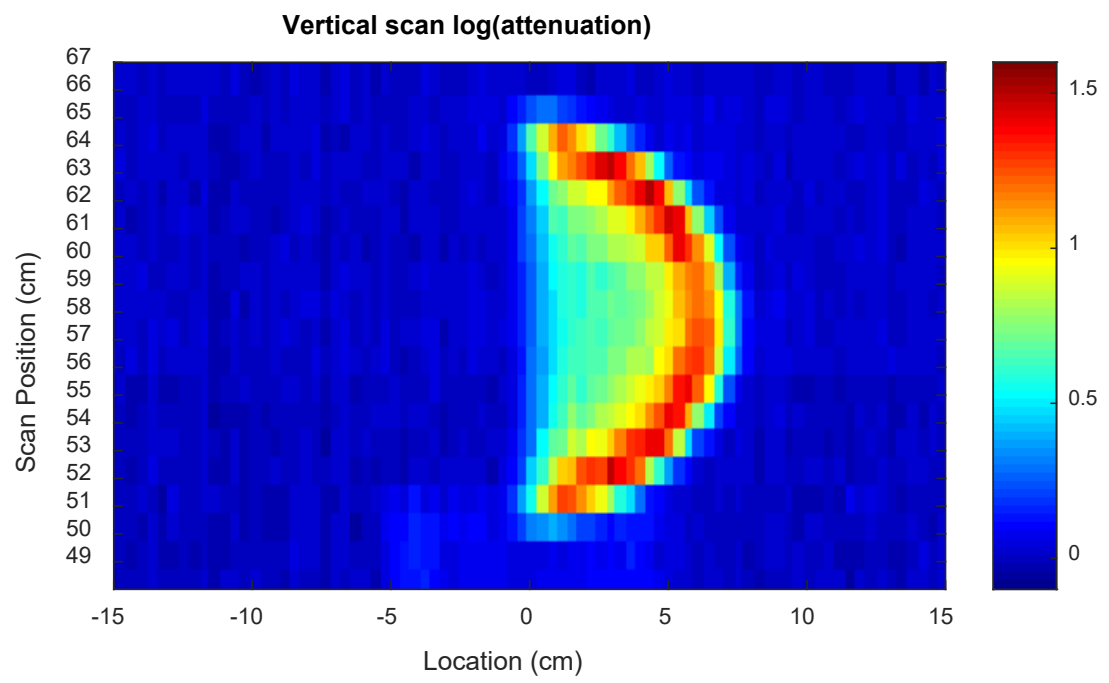

Figure 8. Reconstructed images for the hemispherical steel shell at $90^{\circ}$ from NMIS.

\subsubsection{ONV Letters}

The cross-sectional transmission image was obtained at the mid-vertical height. The reconstructed crosssectional image is shown in Figure 9. For this image, 60 rotational angles were used with four $51 \mathrm{~s}$ subsamples of data. 


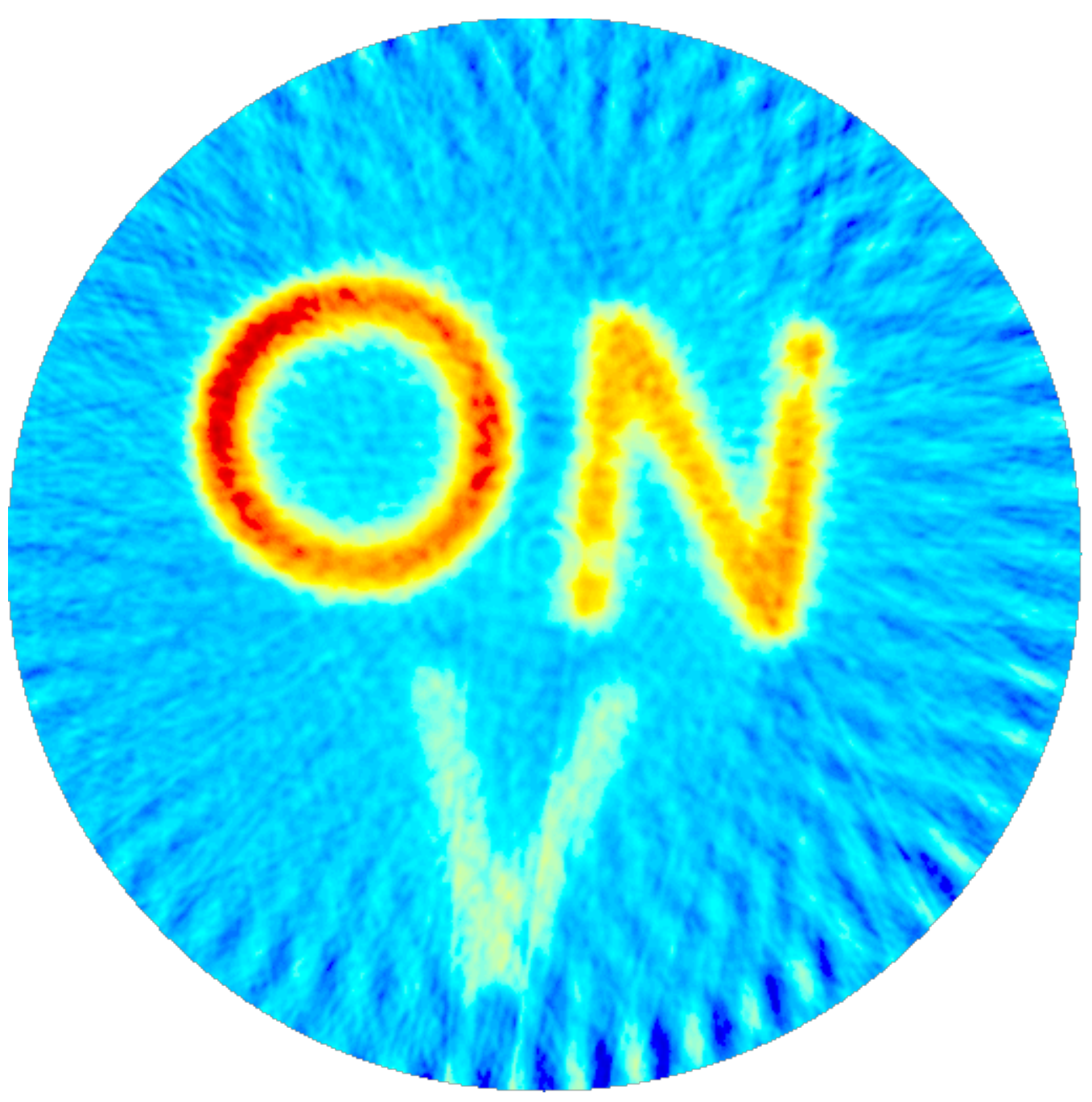

Figure 9. Reconstructed image of the ONV letters from NMIS.

\subsection{FNMIS MEASUREMENTS}

These measurements were taken under the same conditions, as closely as practical, as those for NMIS. The CFD threshold settings were varied while the generator was operating, which is one of the advantages of FNMIS's software. The thresholds for the imaging detectors were also changed. A slight variation over time could have occurred, so these settings and count rates varied slightly.

\subsubsection{Hemispherical Steel Shell}

The hemispherical steel shell in FNMIS at the three angular locations is shown in Figure 10. 

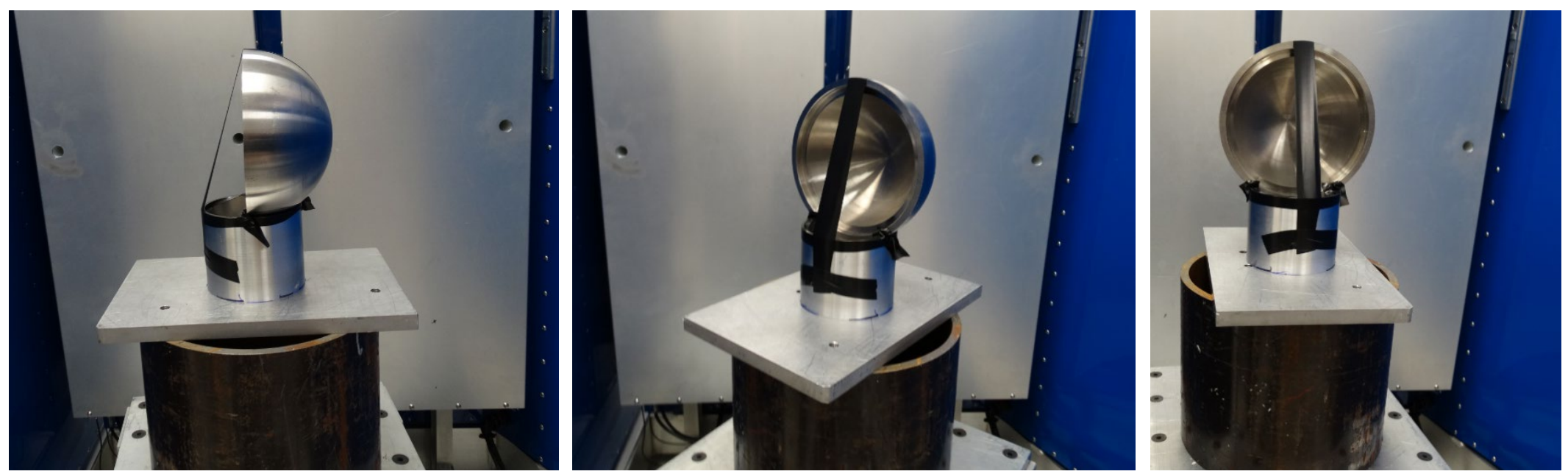

Figure 10. The hemispherical steel shells in three orientations in FNMIS. 
Each of the three imaging measurements was performed with the API generator \#103 operating at $90 \mathrm{KV}$ and $50 \mu \mathrm{A}$ beam current, with six subsamples, $102 \mathrm{~s}$ of data for each subsample, and height steps of 1.0. $\mathrm{cm}$. Only a few rotations were performed to save generator operation time, $45^{\circ}$ and $90^{\circ}$. The equatorial plane of the hemispherical shell at the orientation shown in Figure 5 was $50 \mathrm{~cm}$. The images are plotted in Figures 11-13.

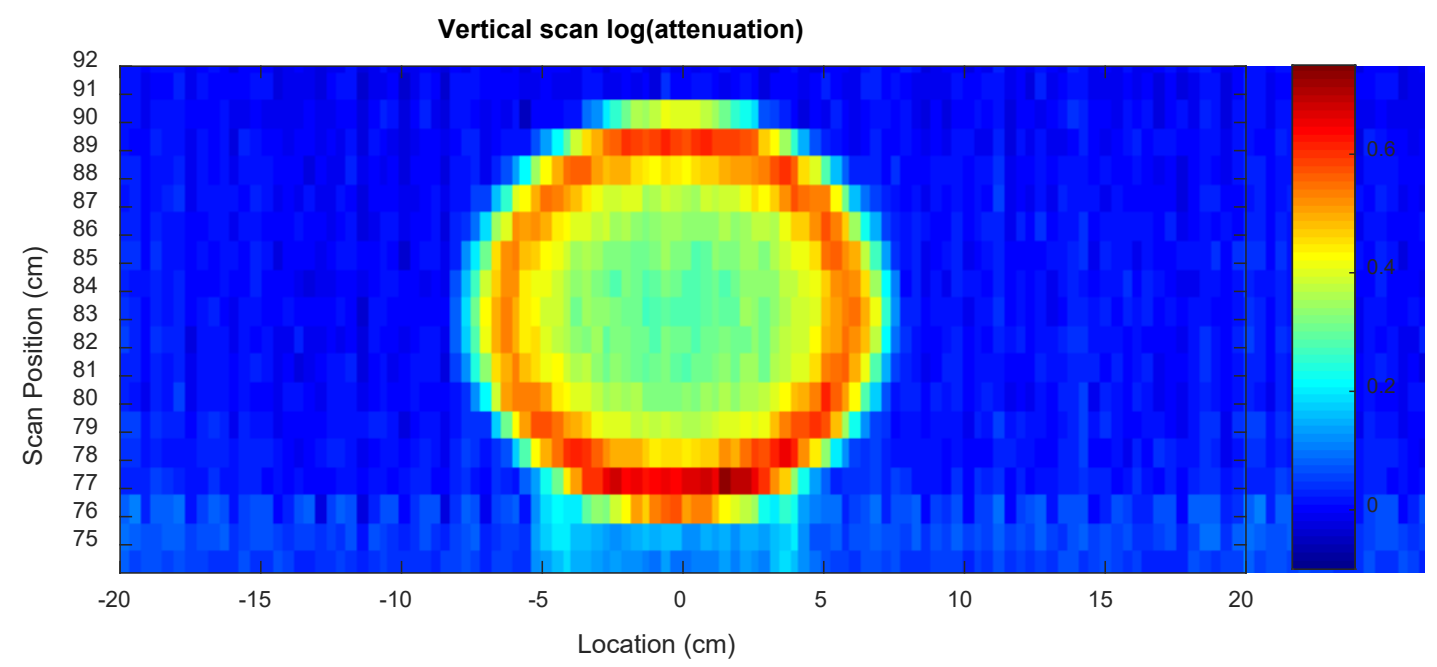

Figure 11. Reconstructed images for the hemispherical steel shell at $0^{\circ}$ from FNMIS.

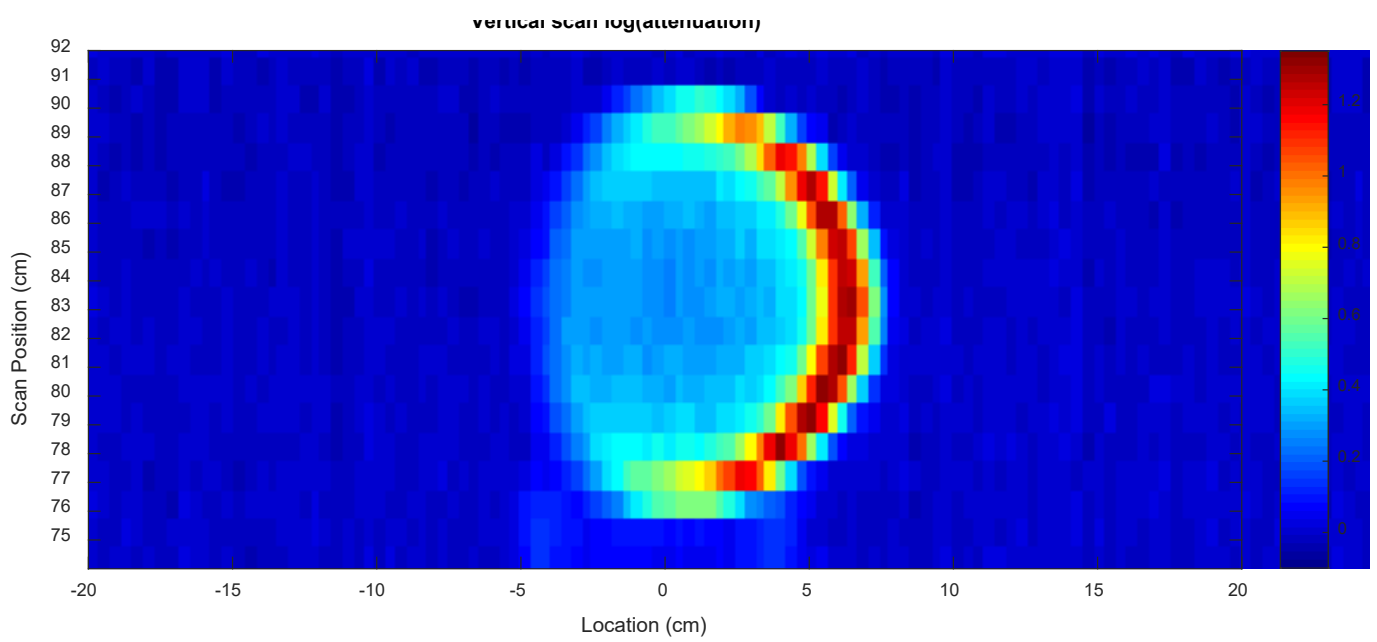

Figure 12. Reconstructed image for the hemispherical steel shell at $45^{\circ}$ from FNMIS. 


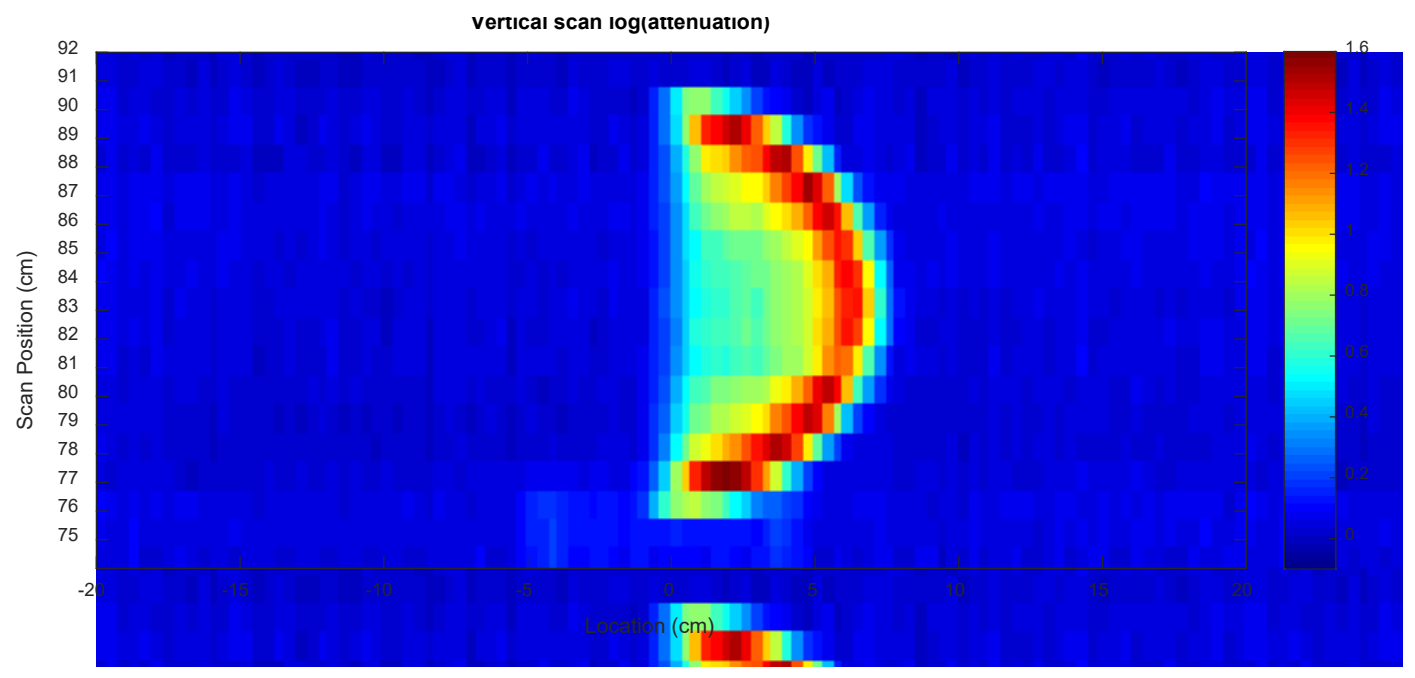

Figure 13. Reconstructed images for the hemispherical steel shell at $90^{\circ}$ from FNMIS.

\subsubsection{ONV letters}

The configuration of the ONV letters in FNMIS is shown in Figure 14.

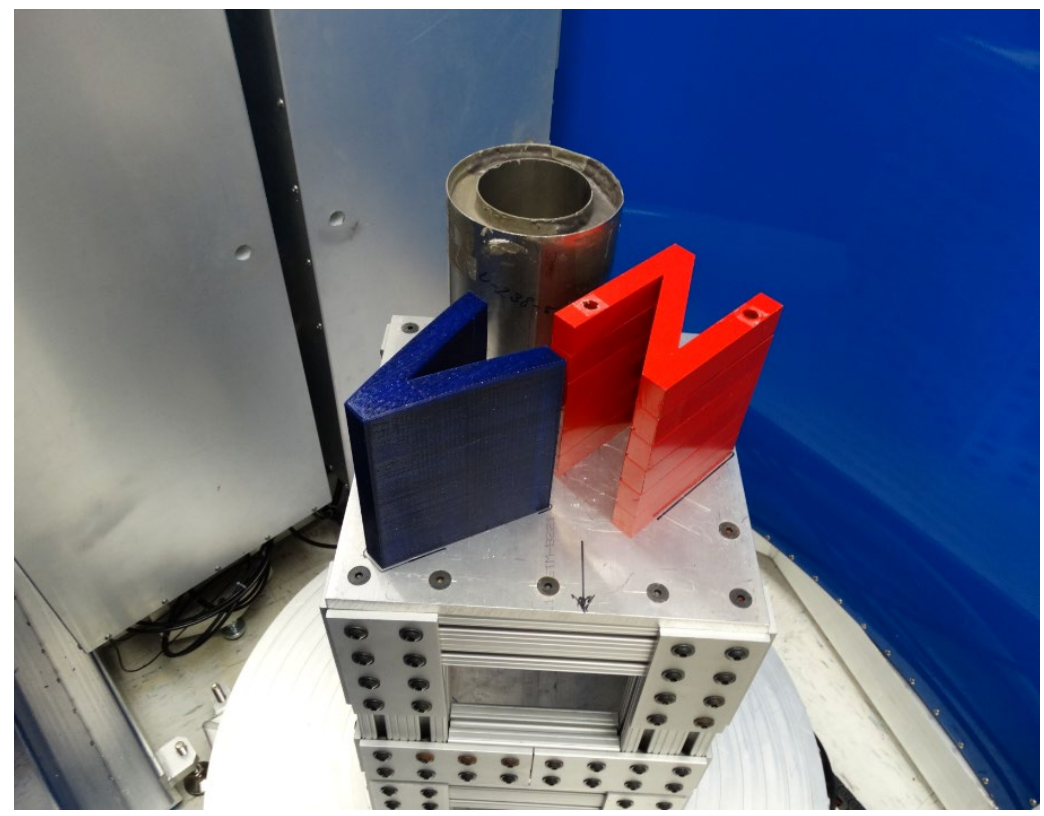

Figure 14. ONV letters in FNMIS.

The cross-sectional image was obtained at the mid-vertical height. The transmission image is shown in Figure 15. For this image, 60 rotational angles were used with four $51 \mathrm{~s}$ subsamples of data. 


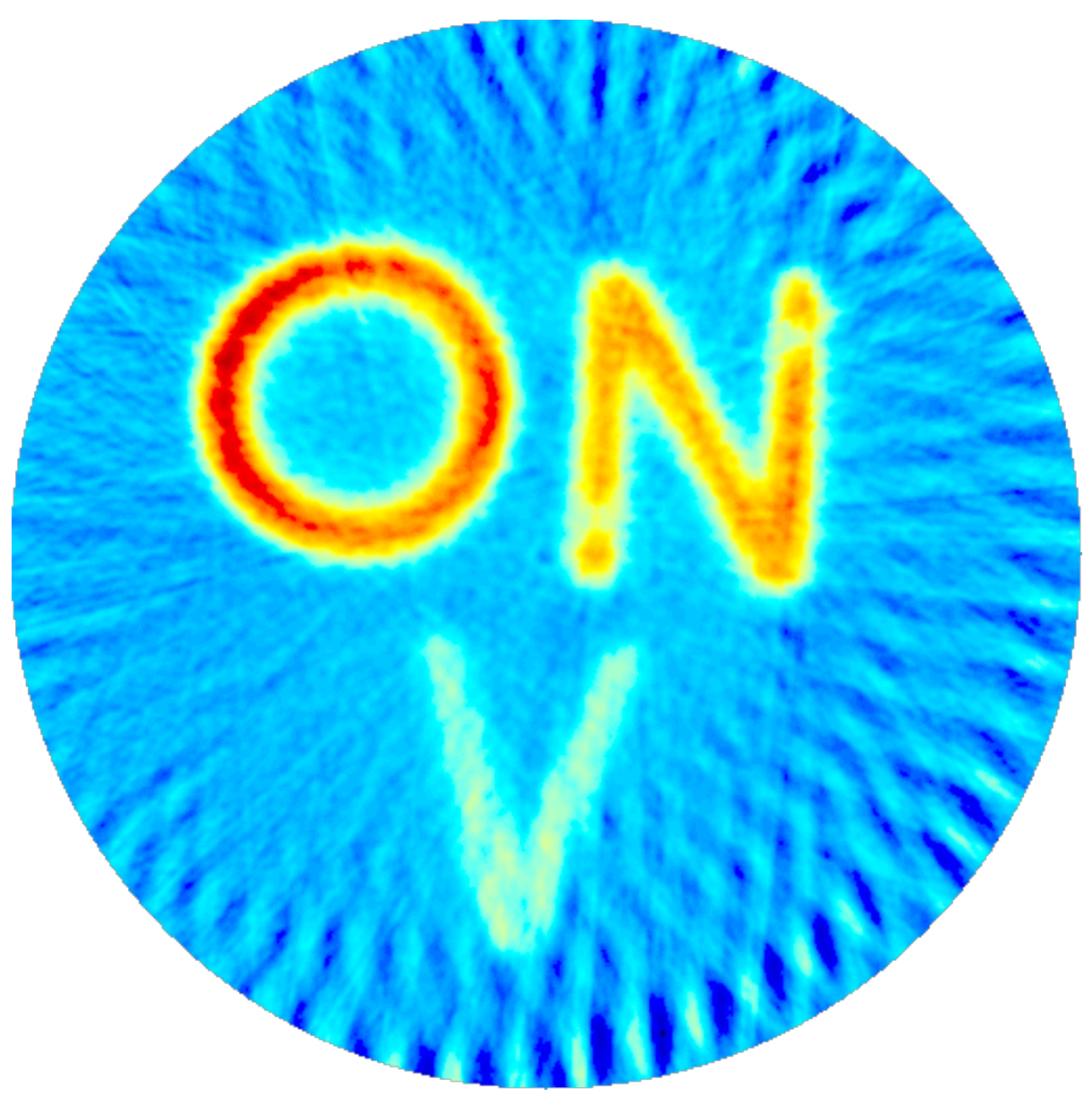

Figure 15. Reconstructed image of the ONV letters from FNMIS.

\subsection{MEASUREMENT TIME DIFFERENCES AND COMPARISON}

Because NMIS and FNMIS both use the same basic DAQ software, the measurement times were not substantially different. The time required to obtain the NMIS image in Figure 9 was 13,485 s, and the time to acquire the FNMIS image in Figure 15 was 12,880 s. The FNMIS DAQ was about 5\% faster than NMIS and was probably because of the different speeds of the motors. The same software was used in both systems to acquire and process the images, so the quality of the images was not substantially different.

\section{NEUTRON GENERATOR OPTIONS}

\subsection{STATUS OF API DT NEUTRON GENERATORS FOR US NMIS/FNMIS}

NMIS has traditionally used a Thermo-Fisher Scientific API-120 with an alpha detector format based on a fiber-optic faceplate. ORNL currently has two functional API-120s with a fiber-optic faceplate. The ion source is the common cause of API-120 failure because the small, but nontrivial, frequency of accelerator voltage arcs during normal operation. Arcing disrupts the nominal operation of the ion source and is apparent when the beam current feedback becomes nonuniform. After enough arcs, the ion source will not function at high-voltage or beam current settings and must be replaced. The ion source lifetime can be extended by reducing the accelerator voltage, which in turn reduces the maximum neutron yield. ORNL has observed ion source failures in four of the five API-120s purchased over the past decade, after fewer 
than $500 \mathrm{~h}$ of neutron production. About half of these failures have occurred while the warranty was still in effect. ORNL expects the remaining API-120s to be functional for another $2-5 \mathrm{y}$.

For fabrication reliability reasons, Thermo-Fisher Scientific transitioned from a fiber-optic faceplate to a sapphire viewport. This transition took place during early development of the FNMIS project. A preliminary assessment of the sapphire viewport format suggested that hardware and software would have to be revised to some degree; therefore, the sapphire viewport was deemed unsuitable as a drop-in replacement for the fiber-optic faceplate. However, the VNIIA ING-27 could be fabricated with a siliconsemiconductor geometry appropriate for the FNMIS design and could be implemented without changing the DAQ hardware and software. Therefore, ORNL purchased an ING-27 using NA-22 FNMIS funds in fiscal year 2013 .

\subsection{API DT NEUTRON GENERATOR OPTIONS}

The commercial options for API DT neutron generators are shown in Table 2. The characteristics listed are based on either experience at ORNL or communications with the vendor.

Table 2. Commercial options for API DT neutron generators

\begin{tabular}{|c|c|c|c|}
\hline Model & API-120 & DT108API & ING-27 \\
\hline Vendor & Thermo-Fisher Scientific & Adelphi Technology & VNIIA \\
\hline Location & USA & USA & Russia \\
\hline Maximum yield & $\begin{array}{l}4 \times 10^{7} \mathrm{n} / \mathrm{s} \text { for } 5 \mathrm{~mm} \text { spot } \\
\text { size }\end{array}$ & $\begin{array}{l}1 \times 10^{8} \mathrm{n} / \mathrm{s} \text { for } 2 \mathrm{~mm} \mathrm{spot} \\
\text { size }\end{array}$ & $\begin{array}{l}8 \times 10^{7} \mathrm{n} / \mathrm{s} \text { for } 3 \mathrm{~mm} \mathrm{spot} \\
\text { size }\end{array}$ \\
\hline Lifetime & $1,200 \mathrm{~h}$ at $1 \times 10^{7} \mathrm{n} / \mathrm{s}$ & $2,000 \mathrm{~h}$ at $1 \times 10^{8} \mathrm{n} / \mathrm{s}$ & $1,000 \mathrm{~h}$ at $8 \times 10^{7} \mathrm{n} / \mathrm{s}^{*}$ \\
\hline $\begin{array}{l}\text { Alpha detector } \\
\text { format }\end{array}$ & $\begin{array}{l}\text { YAP: Ce embedded in } \\
\text { sapphire viewport readout } \\
\text { with photomultiplier tube }\end{array}$ & $\begin{array}{l}\mathrm{ZnO}: \mathrm{Ga} \text { affixed to quartz } \\
\text { viewport readout with } \\
\text { photomultiplier tube }\end{array}$ & $\begin{array}{l}\text { Silicon semiconductor } \\
\text { detector }\end{array}$ \\
\hline $\begin{array}{l}\text { Cost (excluding } \\
\text { overhead) }\end{array}$ & $\$ 85 \mathrm{~K}$ & $\$ 178 \mathrm{~K}$ & $\$ 125 \mathrm{~K}$ \\
\hline
\end{tabular}

*Lifetime of the ING-27 is determined by the alpha detector. VNIIA can replace the alpha detector for approximately $\$ 90 \mathrm{~K}$.

\subsubsection{API-120 Discussion}

During the FNMIS development, it was apparent that some research and development would be required to determine whether the sapphire viewport could be instrumented appropriately for NMIS DAQ electronics. To read out the signals from the fiber-optic faceplate, ORNL uses a custom-designed light guide to direct enough light to a single pixel of a position-sensitive PMT (Hamamatsu H9500). The PMT signals are input to a CFD and an appropriate threshold distinguishes between alpha signals and background signals originating from incident x-rays. ORNL would need to investigate what light guide design, if any, would be sufficient for interfacing between the sapphire viewport and H9500. ThermoFisher Scientific is currently refurbishing two API-120s for the active fast-neutron imagers involved in Suite I of the Warhead Measurement Campaign. Because ORNL needs to test the newly refurbished API120 s, there may be a small window of opportunity to test a sapphire viewport with the existing light guide that is used for FNMIS. 
If the existing light guide is not sufficient, then there will be two paths forward.

1. Design a new light guide using a light transport model, such as Geant4. This approach assumes the same NMIS DAQ functionality of processing event time-of-arrivals. The light guide could be tested with a vacuum chamber like the one currently used to test YAP:Ce crystal performance with the sapphire viewport for the Suite I imagers. Further testing of the light guide could occur when the API-120s return after the Warhead Measurement Campaign or if a new API-120 is purchased.

2. Begin transitioning to a new data acquisition setup that processes pulse height in addition to timeof-arrival. The Suite I imagers have more advanced DAQ electronics that are suitable for reading out the signals from the sapphire viewport. The entire H9500 is instrumented as opposed to a single row of anodes as with NMIS. A custom four-corner readout board for the H9500 enables Anger logic to be used to isolate the location of the alpha event. With this approach, all light detected by the PMT is analyzed to enhance the ability to distinguish between alphas and x-rays. Additionally, the YAP:Ce crystal is fabricated for the sapphire viewport so that a light guide is not required. This approach would also resolve the issue of the aging NMIS DAQ board technology. Incidentally, NA-22 is funding a project with Lawrence Livermore National Laboratory and ORNL to develop a fieldportable secondary emission imaging system. One of the desired outcomes of this project is the acquisition of a commercial DAQ system that can read out the sapphire viewport including all necessary software development.

Either path is expected to enable FNMIS to use the API-120 with the sapphire viewport. The first path using an existing light guide or designing a new light guide with the NMIS DAQ functionality represents a more near-term solution than the second path transitioning to a new DAQ system. If the first path is successful so that processing event times-of-arrival only represents NMIS DAQ for the foreseeable future, a commercial TDC solution to replace the aging NMIS DAQ boards is advised.

\subsection{OTHER POTENTIAL GENERATORS}

\subsubsection{DT108API Discussion}

John Mihalczo corresponded with Adelphi Technology Inc. about using the DT108API in FNMIS. Adelphi fabricated the DT108API with a ZnO:Ga affixed to a quartz viewport. ZnO:Ga has a lower light yield than YAP:Ce, making it more challenging to use with a light guide in the FNMIS. Additionally, the DT108API has a larger footprint than the API-120 with a $50 \mathrm{lb}$. head, $100 \mathrm{lb}$. control and power rack, and a $30 \mathrm{lb}$. heat exchanger. In contrast, the entire API-120 weighs about $30 \mathrm{lb}$. The DT108API requires reengineering to reduce the footprint for use with the FNMIS.

Regarding the alpha detector, installing a YAP:Ce crystal with the appropriate viewport should be possible for the DT108API. However, per the success of using the silicon semiconductor layout in the ING-27, Mihalczo has proposed two rows of $64 \mathrm{SiC}$ detectors total located $10 \mathrm{~cm}$ from the target spot to provide correlated neutron cones narrower than currently available with the ING-27. The advantage of narrower neutron cones is reduced background originating from scatter in the item. Reducing the background improves the imaging contrast and reduces the measurement time. The SiC detector array would span an opening angle of $60^{\circ}$. To address the footprint, Adelphi has agreed to engineer the DT108API with a smaller size and weight. The improved DT108API would weigh less than $50 \mathrm{lb}$. Excluding the DC power supplies to power the DT108API, the footprint is estimated to be $38 \mathrm{~cm}$ long, $15 \mathrm{~cm}$ wide, and $20 \mathrm{~cm}$ deep. The maximum yield is estimated to be $4 \times 10^{8} \mathrm{n} / \mathrm{s}$. A concept of the DT108API engineered with a smaller footprint is shown in Figure 16. 


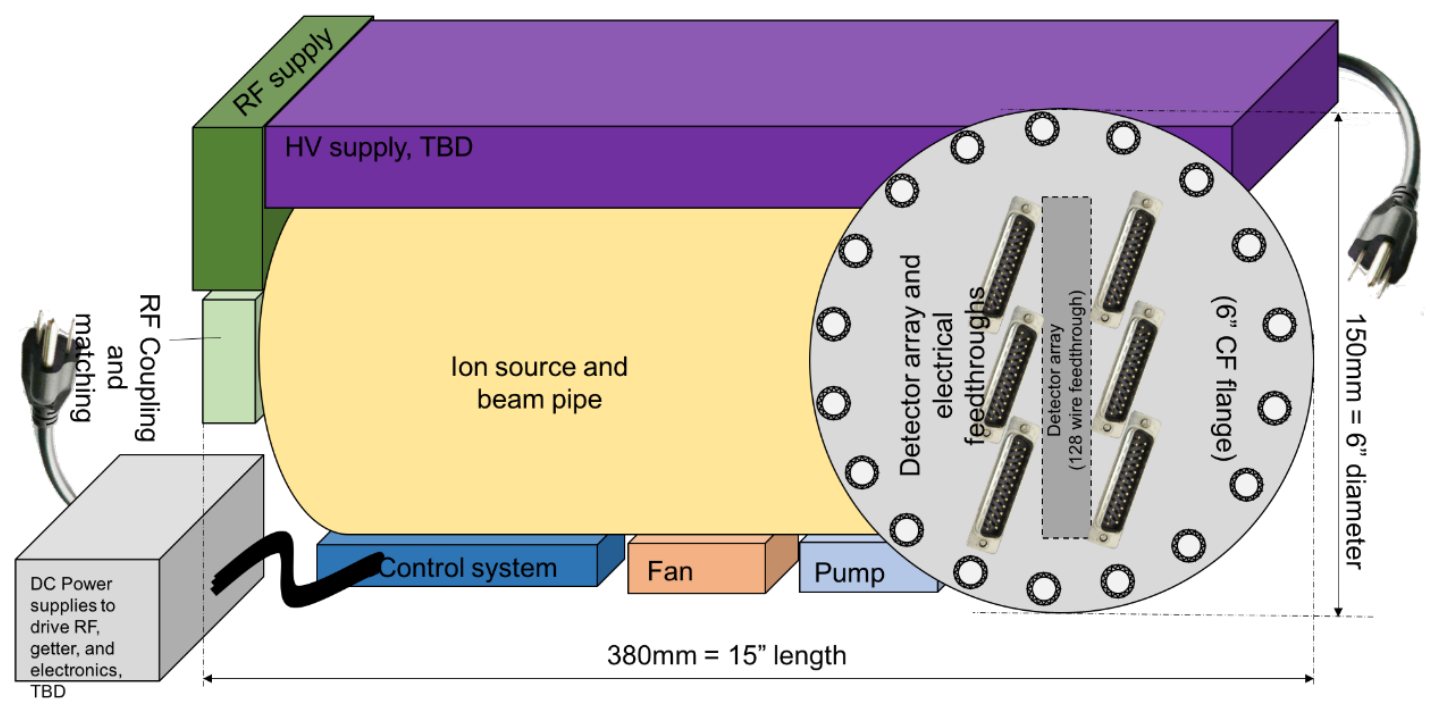

Figure 16. Concept of the DT108API engineered with a smaller footprint. This image is proprietary to Adelphi Technology Inc.

The cost to incorporate a $\mathrm{SiC}$ detector array and engineer a smaller footprint is $\$ 325 \mathrm{~K}$. Per correspondence from November 2016, Adelphi quoted a delivery date of mid-2018. For a target spot size of $2 \mathrm{~mm}$, maximum yield of $4 \times 10^{8} \mathrm{n} / \mathrm{s}$, and a $60^{\circ}$ opening angle, the images produced by FNMIS would be an improvement over those produced with the API-120. A paper study to determine the improvement as a function of target spot size and yield may be helpful for justifying the cost to incorporate the DT108API.

\subsubsection{ING-27 Discussion}

The ING-27 with a single row of 15 pixels has worked well as a substitute for the API-120 in the NMIS. The neutron cones are narrower than those for the API-120, and the maximum yield is approximately a factor of two more than the API-120. Additionally, the silicon detector has demonstrated less cross-talk (events in one detector being counted in another) noise than the H9500 readout of the fiber-optic faceplate. Assuming FNMIS continues to use the time-of-arrival event-based DAQ, a neutron generator like the ING-27 would be suitable for FNMIS. ORNL has a purchase order for an ING-27 generator with an output of $2 \times 10^{8} \mathrm{n} / \mathrm{s}$. It will be delivered at the end of 2017. ORNL has also asked VNIIA for the cost of a generator that meets the requirements of the Adelphi generator described in the previous section.

\subsubsection{Other Potential Vendors for API DT Neutron Generators}

Another potential vendor of API DT neutron generators is Sodern, which appears to be under PT Global Haditech Corporation. Sodern was contacted early in FNMIS development as a commercial option for an API DT neutron generator. Their response was that the request was interesting, but the market was too small. Sodern has been contacted to determine if their position has changed.

\subsubsection{Research and Development Path}

ORNL has previously proposed developing an API DT neutron generator per the NA-221 proposal calls. Such a generator would be generally useful for transportable active fast-neutron imaging. This proposal leverages the hardware development as part of the Defense Advanced Research Projects Agency Intense and Compact Neutron Sources project, which ORNL participates in. The proposal is available on request. 


\section{CONCLUSIONS}

NMIS is a research system that can easily be modified and used in a variety of research applications. It is an open system but is not compatible with an information barrier, which is needed for treaty applications. Because it is an open system, it is easy to replace failed components. FNMIS is a modular closed system that was designed to be compatible with an information barrier, making it more suitable for the ONV mission. Being a closed system makes it more difficult to repair failed components but not enough to preclude its usefulness. There were no substantial differences in the quality of the images obtained from both.

\section{REFERENCES}

[1] J. T. Mihalczo, P. R. Bingham, M. A. Blackston, J. M. Crye, B. R, Grogan, P. A Hausladen, S. M. McConchie, and J. A. Mullens, "Fast Neutron Imaging with API DT Neutron Generators" Proceedings of the International Scientific and Technical Conference on Portable Neutron Generators and Technologies and their Basis, All Russian Institute of Automatics (VNIIA) Moscow, October 2012.

[2] J. T. Mihalczo, J. A. Mullens, J. K. Mattingly, and T. E. Valentine, "Physical Description of Nuclear materials Identification System Signatures," Nuclear Instruments and Methods in Physics Research A, 450, 531-55 (2000).

[3] J. E. Breeding, J. A. Mullens, G. W. turner, J. A. McEvers, M. C. Smith, D. E. McMillan, T. E. Valentine, J. T. Mihalczo, and T. A. Gaffford, "New Processor for Fissile System Measurements for NMC\&A" Proceedings of the 38th Annual Meeting of the Institute of Materials Management, Phoenix, AZ (July 1997). 